(C) 2022, The Authors. Published by Elsevier Inc. and Fass Inc. on behalf of the American Dairy Science Association ${ }^{\circledR}$. This is an open access article under the CC BY license (http://creativecommons.org/licenses/by/4.0/).

\title{
Milk metabolites and fatty acids as noninvasive biomarkers of metabolic status and energy balance in early-lactation cows
}

\author{
J. A. A. Pires, ${ }^{1 *}$ (1) T. Larsen, ${ }^{2}$ () and C. Leroux ${ }^{1}$ (๑) \\ ${ }^{1}$ INRAE, Université Clermont Auvergne, Vetagro Sup, UMRH, 63122, Saint-Genès-Champanelle, France \\ ${ }^{2}$ Departmemt of Animal Science, Aarhus University, 8830, Tjele, Denmark
}

\begin{abstract}
The objective was to study the effects of week of lactation (WOL) and experimental nutrient restriction on concentrations of selected milk metabolites and fatty acids (FA), and assess their potential as biomarkers of energy status in early-lactation cows. To study WOL effects, 17 multiparous Holstein cows were phenotyped from calving until 7 WOL while allowed ad libitum intake of a lactation diet. Further, to study the effects of nutrient restriction, 8 of these cows received a diet containing $48 \%$ straw (high-straw) for $4 \mathrm{~d}$ starting at 24 \pm 3 days in milk (mean $\pm \mathrm{SD}$ ), and 8 cows maintained on the lactation diet were sampled to serve as controls. Blood and milk samples were collected weekly for the WOL data set, and daily from d -1 to 3 of nutrient restriction (or control) for the nutritional challenge data set. Milk $\beta$-hydroxybutyrate (BHB), isocitrate, glucose, glucose-6-phosphate (glucose-6P), galactose, glutamate, creatinine, uric acid, and $N$-acetyl- $\beta$-Dglucosaminidase activity (NAGase) were analyzed in p.m. and a.m. samples, and milk FA were analyzed in pooled p.m. and a.m. samples. Average energy balance (EB) per day ranged from $-27 \mathrm{MJ} / \mathrm{d}$ to neutral when cows received the lactation total mixed ration, and from -109 to $-87 \pm 7 \mathrm{MJ} / \mathrm{d}$ for high-straw (least squares means \pm standard error of the mean). Plasma nonesterified FA concentration was $1.67 \pm 0.13 \mathrm{mM}$ and $\mathrm{BHB}$ was $2.96 \pm 0.39 \mathrm{~m} M$ on the $\mathrm{d} 3$ of high-straw (least squares means \pm standard error of the mean). Milk concentrations of BHB, glucose, glucose-6P, glutamate, and uric acid differed significantly between p.m. and a.m. milkings. Milk isocitrate, glucose-6P, creatinine, and NAGase decreased, whereas milk glucose and galactose increased with WOL. Changes in milk BHB, isocitrate, glucose, glucose-6P, and creatinine were concordant during early lactation and in response to nutrient restriction. Milk galactose and NAGase were
\end{abstract}

Received March 16, 2021.

Accepted August 23, 2021.

*Corresponding author: jose.pires@inrae.fr modulated by WOL only, whereas glutamate and uric acid concentrations responded to nutrient restriction only. The high-straw increased milk concentrations of FA potentially mobilized from adipose tissue (e.g., C18:0 and cis-9 C18:1 and sum of odd- and branchedchain FA (OBCFA) with carbon chain greater than 16; $\Sigma$ OBCFA $>$ C16), and decreased concentrations of FA synthesized de novo by the mammary gland (e.g., sum of FA with 6 to 15 carbons; $\Sigma$ C6:0 to C15:0). Similar observations were made during early lactation. Plasma nonesterified FA concentrations had the best single linear regression with $\mathrm{EB}\left(\mathrm{R}^{2}=0.62\right)$. Milk isocitrate, $\Sigma$ C6:0 to C15:0. and cis-9 C18:1 had the best single linear regressions with $\mathrm{EB}\left(\mathrm{R}^{2} \geq 0.44\right)$. Milk BHB, isocitrate, galactose, glutamate, and creatinine explained up to $64 \%$ of the EB variation observed in the current study using multiple linear regression. Milk concentrations of $\Sigma$ C6:0 to C15:0, C18:0, cis-9 C18:1, and $\Sigma$ OBCFA $>$ C16 presented some of the best correlations and regressions with other indicators of metabolic status, lipomobilization, and EB, and their responses were concordant during early lactation and during experimental nutrient restriction. Metabolites and FA secreted in milk may serve as noninvasive indicators of metabolic status and EB of early-lactation cows.

Key words: dairy cow, energy balance, milk metabolite, milk fatty acid

\section{INTRODUCTION}

Dairy cows often experience negative energy balance (EB), mobilize body reserves, and are at heightened risk for several metabolic disorders during early lactation. Long periods of negative EB and excessive BCS loss are associated with hepatic lipidosis, ketosis, and altered immune and reproductive function (Grummer, 1993; Hammon et al., 2006; Butler, 2014). It has been suggested that systemic inflammation and oxidative stress may further challenge nutrient homeostasis mechanisms and play a pivotal role for successful transitioning through early lactation (Zachut et al., 2016; Pires et al., 2019; Horst et al., 2021). On-farm 
monitoring of individual cow EB is challenging because estimation of energy requirements and energy intake requires frequent measurements of DMI, BW, and milk composition. Individual BCS changes over time and provides only a retrospective assessment of energy status because detectable BCS changes are delayed relative to the onset of fat mobilization and associated metabolic stress. Furthermore, BCS is insensitive to detection of transient variations in EB (Friggens et al., 2007; Chagas et al., 2009; Pires et al., 2015).

Metabolic and mineral status of periparturient dairy cows are often monitored by blood sampling for herd troubleshooting (Oetzel, 2004; Overton et al., 2017), and extreme metabolic deviations during early lactation are associated with increased risk of culling (Roberts et al., 2012). Milk may be a preferred matrix whenever possible because it is noninvasive and convenient to collect, and it is commonly used to monitor ketosis (Oetzel, 2004; Pralle and White, 2020). Variations in milk fat content and milk FA composition are indicators of lipomobilization. Fatty acids are a major milk component, and FA profile is modulated by diet and mobilization of adipose tissue in response to negative $\mathrm{EB}$, such as during early lactation and periods of induced undernutrition (Gross et al., 2011a; Pires et al., 2013; Billa et al., 2020). Because C18:0 and C18:1 may constitute more than $50 \%$ of fatty acids (FA) in dairy cow adipose tissue (Leiber et al., 2011; Hostens et al., 2012; Lerch et al., 2015) and plasma nonesterified fatty acids (NEFA; Scalia et al., 2006), the increase in milk content of these FA reflect body fat mobilization. The concomitant decrease in FA with carbon chains shorter than 16 result in part from downregulation of de novo FA synthesis due to limiting availability of precursors for FA synthesis in the mammary gland (Gross et al., 2011a; Pires et al., 2013; Billa et al., 2020). Thresholds of major milk FA and FA ratios have been proposed to detect cows experiencing excessive lipomobilization and ketosis (Jorjong et al., 2014; Jorjong et al., 2015; Dórea et al., 2017).

Metabolites are minor milk constituents that can be modulated by DIM (Larsen et al., 2016; Zachut et al., 2016), diet composition, and feed allowance in dairy cows (Larsen and Moyes, 2015; Billa et al., 2020). Selected milk metabolites have been proposed as biomarkers of nutritional status and mammary gland metabolism, including milk BHB, glucose, glucose-6 phosphate (glucose-6P), isocitrate, glutamate, and uric acid (Larsen et al., 2016; Zachut et al., 2016; Billa et al., 2020). Concentrations of milk metabolites may reflect modifications of their availability in plasma and activity of specific metabolic pathways in mammary epithelial cells (Chaiyabutr et al., 1981; Xu et al., 2018).
For instance, glucose, galactose, isocitrate, and glucose$6 \mathrm{P}$ are part of diverse metabolic pathways, including lactose synthesis, production of reducing potential (i.e., NADPH) associated with FA de novo synthesis, and mitigation of oxidative stress (Chaiyabutr et al., 1981; Zachut et al., 2016; Billa et al., 2020). Milk creatinine was proposed as an indicator of protein mobilization in early-lactation cows (Larsen et al., 2017), whereas milk uric acid may be modulated by ruminal nitrogen metabolism and DMI (Larsen and Moyes, 2010; Billa et al., 2020). Milk metabolomics were recently used to screen for novel metabolites associated with negative EB in early-lactation cows (Xu et al., 2018, 2020a,b).

A variety of nutrient restriction models have been used to induce metabolic deviations, study the effects on different organ and biological functions, and research indicators of metabolic adaptation (Gross et al., 2011b; Bjerre-Harpøth et al., 2012; Billa et al., 2020). We have reported the effects of feed restriction on concentrations of selected milk metabolites and FA in mid-lactation cows (Billa et al., 2020). In that experiment, milk glucose and glutamate concentrations presented the strongest correlations with EB and other indicators of lipomobilization (Billa et al., 2020). Nutrient restrictions performed during early lactation induce greater metabolic deviations than later in lactation (Bjerre-Harpøth et al., 2012). In a previous experiment, feeding a high-straw TMR to earlylactation cows for $4 \mathrm{~d}$ decreased DMI, and induced a negative $\mathrm{EB}(-105$ to $-84 \pm 8 \mathrm{MJ} / \mathrm{d} ; \mathrm{LSM} \pm \mathrm{SEM})$ and marked metabolic deviations, including subclinical ketosis (Pires et al., 2019). In the current study, milk samples collected from the experiment by Pires et al. (2019) were analyzed for FA, BHB, isocitrate, glucose, glucose-6P, galactose, glutamate, creatinine, uric acid, and $N$-acetyl- $\beta$-D-glucosaminidase activity (NAGase). The metabolites analyzed in this study participate in diverse key metabolic pathways of whole-body energy and protein metabolism, and lactose synthesis by the mammary epithelial cell. Therefore, the responses to the 2 models of undernutrition (i.e.; early lactation vs. nutrient restriction) may reflect the diversity of metabolic adaptations that are required to maintain homeostasis in the long- (early lactation) versus short-term (nutrient restriction). We hypothesized that concentrations of milk metabolites and FA would be modified during periods of spontaneous negative EB typical of early lactation, and in response to experimentally-induced nutrient restriction, and that certain milk metabolites and FA may serve as biomarkers of metabolic status and EB. The objectives were to determine the effects of week of lactation (WOL) and experimentally-induced undernutrition on (1) concentrations of selected milk 
metabolites and FA; and (2) associations among concentrations of milk metabolites, FA, EB, and plasma indicators of metabolic status in early-lactation cows.

\section{MATERIALS AND METHODS}

This research is based on an experiment initially designed to assess the effects of undernutrition on responses to acute mammary inflammation in early-lactation cows (Pires et al., 2019). All animal procedures were approved by the Ethics Committee on Animal Experimentation and the French Ministry of Higher Education, Research and Innovation (APAFIS \#2018062913565518). The experiment was conducted in the Herbipôle Research Unit (INRAE, UE1414, Theix, France; https://doi.org/ 10.15454/1.5572318050509348E12).

To assess the WOL effects, 17 multiparous Holstein cows were phenotyped from calving until $7 \mathrm{wk}$ postpartum using data collected when all cows were allowed ad libitum intake of a lactation TMR (Lact-TMR; $7.1 \mathrm{MJ} / \mathrm{kg}$ of $\mathrm{DM} \mathrm{NE} \mathrm{L}_{\mathrm{L}}, 17.4 \% \mathrm{CP}$ ), as described below. A nutritional challenge was performed from 24 to 27 \pm 3 DIM (mean $\pm \mathrm{SD}$ ). During the challenge period, a subset of 8 cows were randomly allocated to $4 \mathrm{~d}$ of nutrient restriction (high-straw). Nutrient restriction was induced by offering a TMR containing 48\% (DM basis) of barley straw $(5.2 \mathrm{MJ} / \mathrm{kg}$ of $\mathrm{DM} \mathrm{NE}$, $12.2 \%$ $\mathrm{CP})$. For the current study, milk samples were collected until $72 \mathrm{~h}$ of nutritional challenge period. Nine cows maintained on the standard Lact-TMR were sampled to serve as controls during the period corresponding to nutritional challenge. Unfortunately, 1 cow assigned to Lact-TMR had missing milk samples for metabolite and FA analyses during the period corresponding to nutritional challenge, and the Lact-TMR group was reduced to 8 cows. Diet composition is reported elsewhere (Pires et al., 2019).

Cows were milked twice daily at approximately 0900 and $1600 \mathrm{~h}$, were offered fresh TMR once daily after morning milking, and had free access to drinking water. Cows were housed in freestalls equipped with individual feed bunks and automatic gates (model "Dairy Gates 3," SODALEC). Cows were transferred to a tiestall barn during the week preceding and the week of the nutritional challenge (or equivalent lactation period for controls). Individual DMI was measured $4 \mathrm{~d} / \mathrm{wk}$, from Monday to Thursday. Offered TMR and refusals were weighed, and DM was determined after $48 \mathrm{~h}$ at $80^{\circ} \mathrm{C}$. Milk yield was measured automatically (DeLaval milk meter MM27BC) and was analyzed for fat, protein, and lactose in 4 consecutive milkings each week (p.m. and a.m. milkings). Milk composition (p.m. and a.m. milkings) and DMI were measured daily during the period corresponding to the nutritional challenge (Pires et al.,
2019). Energy balance was estimated according to the INRA system, as previously described (INRA, 2007; Billa et al., 2020). Blood samples were collected from coccygeal vessels before morning feeding each Wednesday on wk 1, 2, 3, 5, 6, and 7 of lactation (i.e., 8, 15, $21,23,35,42$, and $49 \pm 3$ DIM; mean \pm SD) and from jugular veins at $-24,24,48$, and $72 \mathrm{~h}$ relative to initiation of nutrient restriction or control (i.e., 23, 24, 25, and $26 \pm 3$ DIM; mean \pm SD). Plasma samples were analyzed for glucose, NEFA, BHB, urea, and insulin (Pires et al., 2019). Milk samples were collected from p.m. and a.m. milkings that preceded weekly blood sampling, and from d -1 to $d 3$ relative to nutrient restriction (or control) period. Morning and evening milk samples analyzed separately for BHB, isocitrate, glucose, glucose-6P, glutamate, uric acid (Billa et al., 2020), creatinine (assay based on Jaffe method, after precipitation with 2 parts of $99 \%$ ethanol and centrifugation at $3,500 \times g$ for $10 \mathrm{~min}$ at $21^{\circ} \mathrm{C}$; unpublished data, T. Larsen, Aarhus University, Denmark), galactose [determined by an enzymatic fluorometric method analog to the glucose determination, where galactose dehydrogenase (EC 1.1.1.48) was used as the oxidoreductase; unpublished data, T. Larsen, Aarhus University, Denmark], and NAGase (Larsen et al., 2010). Individual milk samples from consecutive p.m. and a.m. milkings were lyophilized, pooled proportionally to the p.m. and a.m. milk fat yield, and analyzed for milk FA composition by gas-liquid chromatography as previously described (Billa et al., 2020). The milk FA and FA classes presented are sum of FA with 6 to 15 carbons ( $\Sigma$ C6:0 to C15:0), C16, C18, cis-9 C18:1, sum of odd- and branched-chain FA ( $\Sigma$ OBCFA), and sum of OBCFA with carbon chain shorter than $16(\Sigma$ OBCFA $<$ C16) and sum of OBCFA with carbon chain greater than 16 ( $\Sigma$ OBCFA $>$ C16).

At $72 \mathrm{~h}$ of restriction, or at an equivalent period for control cows, 1 mammary quarter was injected with $50 \mu \mathrm{g}$ of LPS (Escherichia coli O111:B4), and mammary gland and liver biopsies were performed $24 \mathrm{~h}$ later (Pawłowski et al., 2016, 2019; Pires et al., 2019). For the current study, samples were not collected during the week that followed LPS injection and biopsies. Furthermore, DMI, milk yield and composition, and EB data on wk 5 corresponded to measurements at 35 DIM. The 7-d washout period allowed the recovery of cows assigned to high-straw TMR to minimize potential carryover effects. Milk yield, milk composition, BW, BCS, $\mathrm{EB}$, plasma metabolite, and insulin concentrations did not differ between the 2 groups at 35 DIM and thereafter (Pires et al., 2019).

Statistical analyses were performed using SAS (version 9.4; SAS Institute Inc.), and correlation heatmaps were produced using the corrplot package of $\mathrm{R}$ (Wei 
and Simko, 2017; http://www.r-project.org). The effect of milking (p.m. vs. a.m.) on concentrations of milk metabolites was studied using data collected when cows were offered the Lact-TMR only. The comparison between p.m. and a.m. milkings was performed by descriptive statistics (MEANS procedure) and mixed models (MIXED procedure) that included milking (a.m. vs p.m.) as the dependent variable, milk metabolite concentration as independent variable, and cow as random effect. Single linear regressions between a.m. and p.m. concentrations were explored using the GLM procedure, where a.m. concentration was coded as a dependent variable and p.m. as an independent variable. All subsequent statistical analyses were performed using milk metabolite concentrations measured from a.m. milkings.

Data were analyzed separately to determine the WOL effects (samples collected at 8, 15, 21, 23, 35, 42, and 49 \pm 3 DIM, when all cows received the Lact-TMR) and nutritional challenge effects (Lact-TMR vs. high-straw; samples collected on $\mathrm{d}-1,1,2,3$ of dietary treatments, corresponding to $23,24,25$, and $26 \pm 3$ DIM). Longitudinal analyses were performed using MIXED procedure that included cow as a random effect, the REPEATED statement to account for repeated measures in time, and day coded as a CLASS variable. To determine WOL effects, statistical models included the fixed effect of day (i.e., 8, 15, 21, 23, 35, 42, and 49 DIM). Alphabetic superscripts denoting differences across time were produced using the pdmix 800 macro (Saxton, 1998) and the Fisher's protected least significant difference defined at $P \leq 0.05$. To determine the effects of nutrient restriction, models included the fixed effects of diet (Lact-TMR vs. high-straw), day (i.e., 23, 24,25 , and 26 DIM), and diet by day interaction. Data collected at 23 DIM were tested as covariates for analyses of the challenge data set. When the covariate was significant, repeated measures analyses were performed using data collected during the challenge (i.e.; 24, 25, and 26 DIM) and the covariate. Kenward-Rogers adjustment was used for denominator degrees of freedom calculations. Different covariance structures were compared using the Schwarz's Bayesian criterion, including spatial power, first-order autoregressive, heterogeneous first-order autoregressive, and compound symmetry. Treatment differences were analyzed at individual time points using the SLICE option when diet or diet by day interaction were significant. Logarithmic transformation was used when needed to comply with the assumptions of normality and homoscedasticity, which were assessed by residual analyses using graphical plots, UNIVARIATE procedure, and residual diagnostics options of MIXED and GLM procedures. When transformations were necessary, least squares means and standard er- ror of the mean were estimated from untransformed values, whereas $P$-values reflect statistical analysis of transformed data. Heterogeneous variance for each diet was tested using the GROUP option of REPEATED statement whenever suggested by residual plots. Values are reported are least squares means and standard error of the mean unless otherwise stated.

Associations among different variables were explored by Spearman rank correlations within each data set (i.e., WOL and nutritional challenge period). Single linear regressions between $\mathrm{EB}$ as the dependent variable and each milk metabolite, milk FA, and plasma metabolites and insulin were further explored using GLM procedure. Differences in regression intercept and slope between the 2 data sets (i.e., WOL vs. nutritional challenge period) were tested by including the effect of data set and data set by independent variable interaction in the model. Multiple linear regressions between $\mathrm{EB}$ as the dependent variable and concentrations of milk metabolites and milk FA were explored using the whole data set (i.e., WOL and nutritional challenge period), and automatic stepwise selection with slstay $=0.05$ and slentry $=0.15$ options of REG procedure, by offering the following to the model: (1) the milk metabolites and 1 milk FA class that presented the best single linear regressions with $\mathrm{EB}\left(\mathrm{R}^{2} \geq 0.40\right.$ in either WOL or nutritional challenge data sets); (2) all milk metabolites; and (3) all milk metabolites plus 1 milk FA class. Only 1 FA class was offered to each model at a time to avoid multicollinearity. Potential multicollinearity among independent variables was controlled by preliminary correlation analyses and by the variance inflation factor option of the REG procedure. Variance inflation factors never exceeded 2.8 for any variable in the multiple linear regression models. The Levene test was used to compare regression residual variances between Lact-TMR and high-straw. For all statistical analyses, the significance level was predefined at $P \leq$ 0.05 , and marginal evidence of significance was considered at $0.05<P \leq 0.10$.

\section{RESULTS}

\section{Comparison of p.m. and a.m. Milkings}

Descriptive statistics of metabolite concentrations in milk collected during p.m. and a.m. milkings are presented in Table 1. These data concern samples collected when cows were offered the Lact-TMR. Concentrations of milk BHB, glucose, glucose-6P, glutamate, and uric acid differed significantly between p.m. and a.m. milkings, whereas milk isocitrate, galactose, and creatinine did not differ (Table 1). Linear regressions between p.m. and a.m. concentrations were significant for all 
variables, but regression $\mathrm{R}^{2}$ was low for milk $\mathrm{BHB}$ and glucose (0.36 and 0.19, respectively; Supplemental Table S1, https://doi.org/10.5281/zenodo.5137874; Pires et al., 2021).

\section{Longitudinal Analyses}

WOL Data Set. Energy balance and plasma NEFA, glucose, and BHB concentrations are presented in Figure 1. Complementary intake, BW, BCS, milk yield, milk composition, plasma urea, and insulin data were published elsewhere (Pires et al., 2019). Energy balance was $-27,-22$, and $-11 \pm 6 \mathrm{MJ} / \mathrm{d}$ on wk 2,3 , and 5 respectively, and neutral thereafter (day effect: $P$ $<0.001$ ). Energy balance was not calculated on wk 1 of lactation because of missing milk composition data. Plasma NEFA and BHB decreased and glucose increased as lactation progressed (day effect: $P<0.001$ ).

Milk metabolite concentrations are presented in Figure 2 and NAGase activity in Supplemental Figure S1 (https://doi.org/10.5281/zenodo.5137874; Pires et al., 2021). Milk isocitrate, glucose-6P, and creatinine were greatest on wk 1 and decreased as lactation progressed (day effect: $P<0.001$ ). We observed a marginal evidence for a decrease in milk BHB with DIM (day effect: $P=0.08)$. Conversely, milk glucose was lowest on wk 1 and increased with DIM (day effect: $P<0.001$ ). Milk galactose decreased from wk 1 to wk 2 (day effect: $P$ $=0.03$ ) and increased significantly from wk 5 through 7. Milk FA concentrations are presented in Figure 3 and Supplemental Figure S2 (https://doi.org/10.5281/ zenodo.5137874; Pires et al., 2021). Significant DIM effect was observed for all FA reported. Concentrations of $\Sigma$ C6:0 to C15:0, C16:0, $\Sigma$ OBCFA, and $\Sigma$ OBCFA $<\mathrm{C} 16$ increased (day effect: $P<0.05$ ), whereas concentrations of C18:0, cis-9 C18:1, and $\Sigma$ OBCFA $>$ C16 decreased with DIM (day effect: $P<0.001$ ).

Challenge Data Set. Energy balance averaged $-109,-96$, and $-87 \pm 7 \mathrm{MJ} / \mathrm{d}$ on d 1,2 , and 3 of highstraw, respectively, and $-14,-8$ and $-7 \pm 6 \mathrm{MJ} / \mathrm{d}$ for cows that remained on the Lact-TMR during the same period (diet effect; $P<0.001$; Figure 1). Plasma NEFA increased to $1.67 \pm 0.13 \mathrm{~m} M$ and BHB increased to $2.96 \pm 0.39 \mathrm{mM}$, whereas plasma glucose decreased to $49.9 \pm 3.7 \mathrm{mg} / \mathrm{dL}$ on the third day of high-straw and differed from concentrations observed in cows that remained on Lact-TMR (slice effect: $P<0.001$; Figure 1).

The nutritional challenge by high-straw increased milk BHB, isocitrate, and creatinine (diet $\times$ day: $P$ $\leq 0.05$; Figure 2 ) and decreased milk glucose, glutamate, and uric acid compared with Lact-TMR (diet effect or diet $\times$ day: $P \leq 0.02)$. Glucose-6P was greater for high-straw than Lact-TMR (diet effect: $P=0.02$; Figure 2). The nutritional challenge by high-straw increased milk concentrations of C18:0, cis-9 C18:1, and $\Sigma$ OBCFA $>$ C16, and decreased $\Sigma$ C6:0 to C15:0, 16:0 and $\Sigma$ OBCFA $<$ C16 (diet effect or diet $\times$ day: $P \leq 0.03$; Figure 3). High-straw tended to decrease $\Sigma$ OBCFA (diet $\times$ day: $P=0.09$; Supplemental Figure

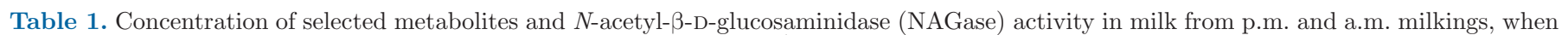
early-lactation cows were allowed ad libitum intake of a lactation $\mathrm{TMR}^{1}$

\begin{tabular}{|c|c|c|c|c|c|c|c|c|c|c|}
\hline Milk variable $(\mu M)$ & Milking & $\mathrm{n}$ & Mean & Max & Min & $\mathrm{SD}$ & Q1 & Median & Q3 & $P$-value ${ }^{2}$ \\
\hline \multirow[t]{2}{*}{ Milk BHB } & p.m. & 139 & 84 & 296 & 27 & 52 & 51 & 68 & 92 & $<0.001$ \\
\hline & a.m. & 139 & 52 & 184 & 20 & 24 & 38 & 47 & 61 & \\
\hline \multirow[t]{2}{*}{ Milk glucose } & p.m. & 138 & 322 & 852 & 48 & 153 & 221 & 277 & 390 & $<0.001$ \\
\hline & a.m. & 138 & 383 & 1,020 & 75 & 178 & 270 & 350 & 466 & \\
\hline \multirow{4}{*}{$\begin{array}{l}\text { Milk glucose-6- } \\
\text { phosphate } \\
\text { Milk isocitrate }\end{array}$} & p.m. & 139 & 196 & 782 & 68 & 101 & 137 & 176 & 233 & 0.02 \\
\hline & a.m. & 139 & 170 & 493 & 37 & 82 & 113 & 159 & 211 & \\
\hline & p.m. & 139 & 126 & 310 & 37 & 52 & 91 & 116 & 156 & 0.21 \\
\hline & a.m. & 139 & 120 & 293 & 39 & 53 & 81 & 105 & 142 & \\
\hline \multirow[t]{2}{*}{ Milk galactose } & p.m. & 138 & 377 & 785 & 179 & 124 & 275 & 350 & 438 & 0.58 \\
\hline & a.m. & 139 & 371 & 849 & 179 & 117 & 291 & 339 & 439 & \\
\hline \multirow[t]{2}{*}{ Milk glutamate } & p.m. & 138 & 347 & 696 & 68 & 120 & 262 & 339 & 430 & $<0.01$ \\
\hline & a.m. & 139 & 318 & 551 & 86 & 98 & 257 & 306 & 385 & \\
\hline \multirow[t]{2}{*}{ Milk uric acid } & p.m. & 139 & 120 & 192 & 57 & 26 & 104 & 123 & 133 & 0.02 \\
\hline & a.m. & 139 & 126 & 227 & 18 & 27 & 111 & 126 & 139 & \\
\hline \multirow[t]{2}{*}{ Milk creatinine } & p.m. & 139 & 234 & 385 & 121 & 34 & 210 & 233 & 251 & 0.43 \\
\hline & a.m. & 139 & 231 & 366 & 127 & 32 & 209 & 228 & 248 & \\
\hline \multirow[t]{2}{*}{ NAGase (U/L) } & p.m. & 139 & 2.6 & 12.6 & 0.8 & 1.8 & 1.4 & 2.0 & 3.0 & 0.20 \\
\hline & a.m. & 139 & 2.3 & 13.0 & 0.8 & 1.7 & 1.4 & 1.8 & 2.5 & \\
\hline
\end{tabular}

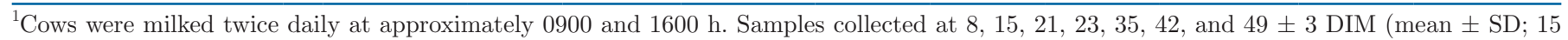
to 17 cows per time point) and at 24, 25, and $26 \pm 3$ DIM (mean \pm SD; 8 cows per time point). Q1 $=$ first quartile; Q3 = third quartile.

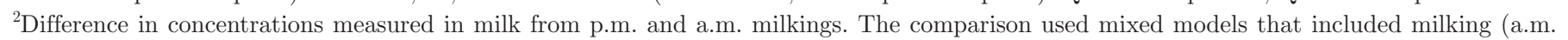

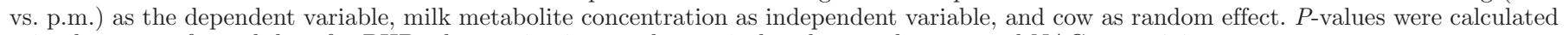
using $\log _{10}$-transformed data for BHB, glucose, isocitrate, glucose-6-phosphate, galactose, and NAGase activity. 
S2, https://doi.org/10.5281/zenodo.5137874; Pires et al., 2021). Treatment differences were not detected on wk 5 through wk 7 for all milk metabolites and FA; therefore, carryover effects of dietary treatments were probably not present.

\section{Correlations}

WOL Data Set. Spearman rank correlations $\left(\mathrm{r}_{\mathrm{s}}\right)$ among EB, milk metabolites, selected milk FA, and plasma indicators of metabolic status are presented in Figures 4 and 5. For data collected between wk 2 to 7 of lactation, and excluding the nutritional challenge period, milk glucose and galactose were positively corre- lated with EB, whereas milk isocitrate, glucose-6P, and creatinine were negatively correlated with EB (Figure $4 \mathrm{~A})$. Milk glucose and creatinine presented the greatest absolute correlations with $\mathrm{EB}\left(\mathrm{r}_{\mathrm{s}}=0.42\right.$ and -0.52 , respectively) among milk metabolites in the WOL data set. No significant correlations with EB were observed for milk BHB, glutamate, and uric acid in the WOL data set. Milk BHB and glucose were correlated with their respective plasma concentrations $\left(\mathrm{r}_{\mathrm{s}}=0.49\right.$ and 0.64 , respectively).

No significant correlations were observed between plasma BHB and EB recorded from wk 2 to 7 of lactation. Plasma NEFA was negatively correlated with EB $\left(r_{\mathrm{s}}=-0.62\right)$, milk BHB, glucose, glucose-6P, isocitrate,
A

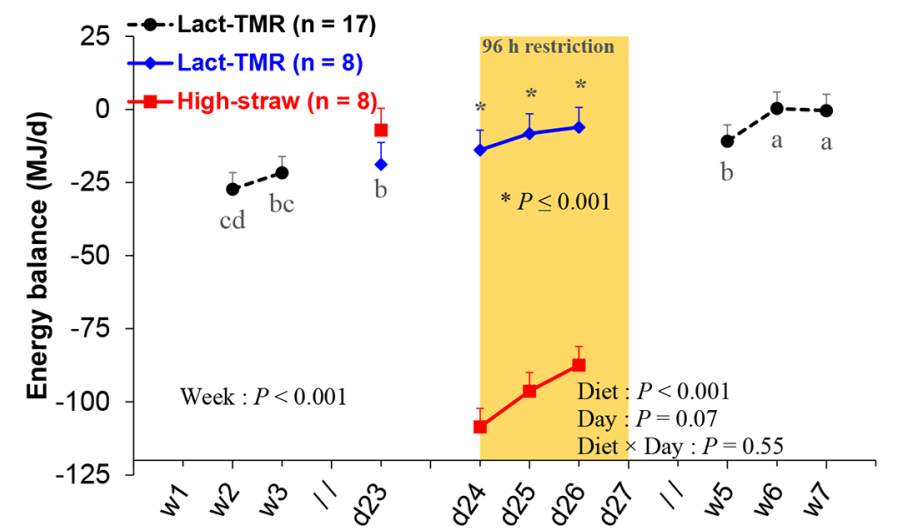

C

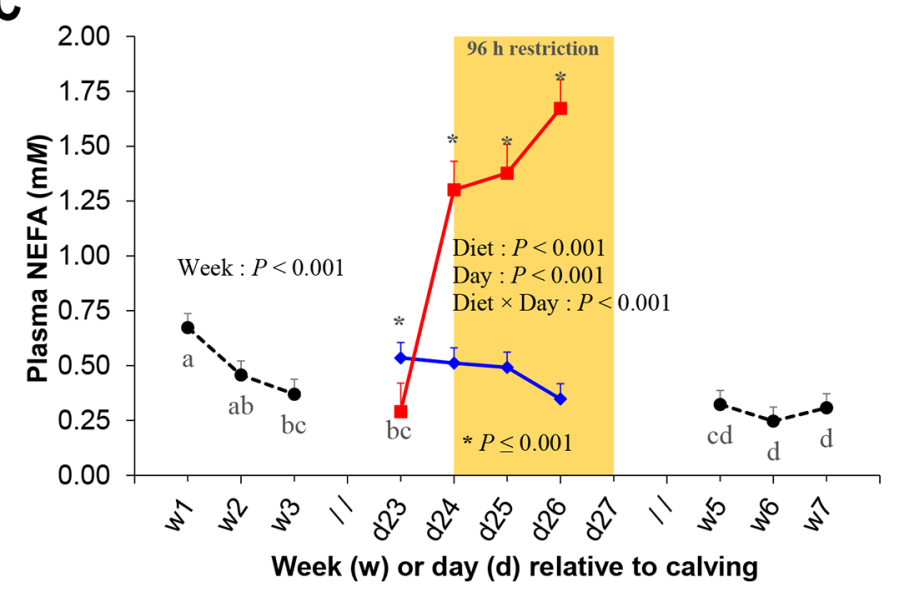

B
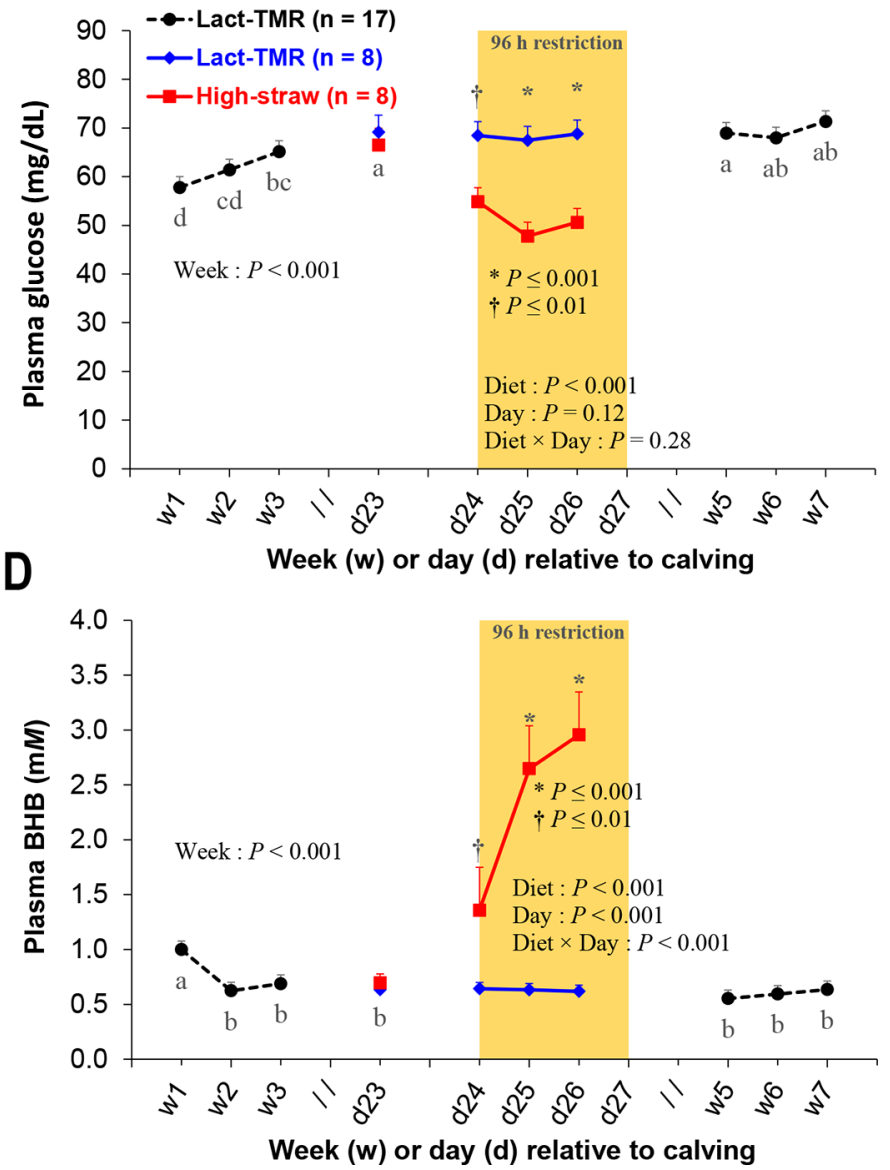

Figure 1. Energy balance (A), plasma glucose (B), nonesterified fatty acids (NEFA; C), and BHB (D) concentrations of early-lactation multiparous Holstein cows. Cows were studied during the first 7 wk of lactation while allowed ad libitum intake of a lactation TMR (Lact-TMR; $\mathrm{n}$ $=17$ ). A subset of 8 cows underwent $4 \mathrm{~d}$ of nutrient restriction (High-straw, $\mathrm{n}=8$ ) from 24 to $27 \pm 3$ DIM (mean \pm SD) by receiving a ration composed of $48 \%$ straw (DM basis). Eight cows maintained on the lactation TMR were sampled during the same period to serve as controls. Data were analyzed separately to assess effects of week of lactation (samples collected at 8, 15, 21, 23, 35, 42, and 49 \pm 3 DIM; mean \pm SD) and nutritional challenge (samples collected at 23, 24, 25, and $26 \pm 3$ DIM; mean \pm SD). Values are presented as LSM \pm SEM. Time points not

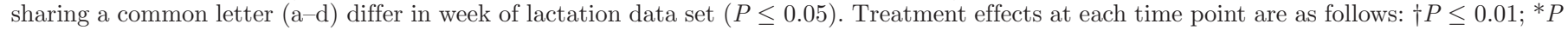

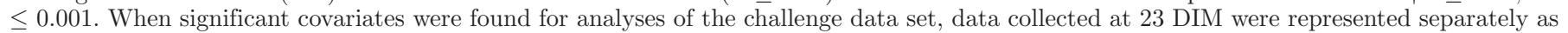
mean and SEM. Adapted from Pires et al. (2019). 
A

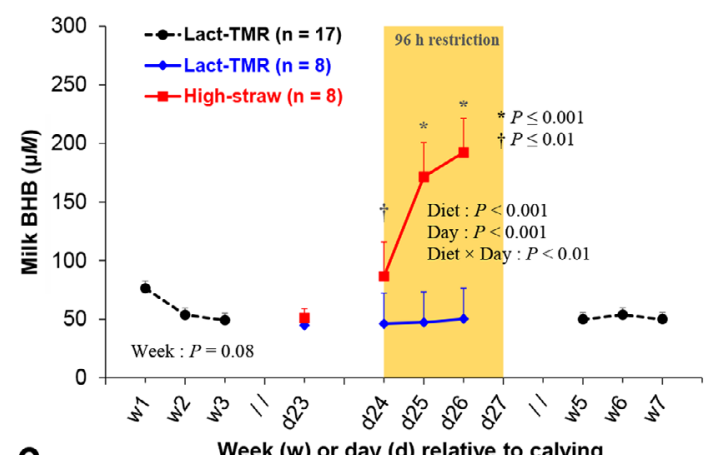

C

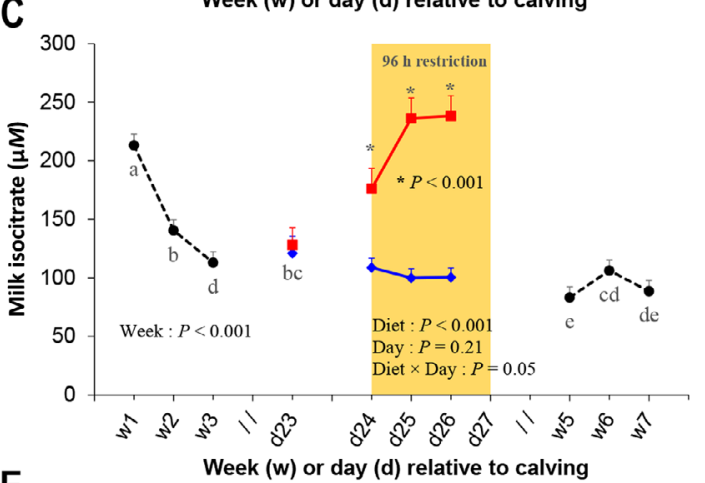

E
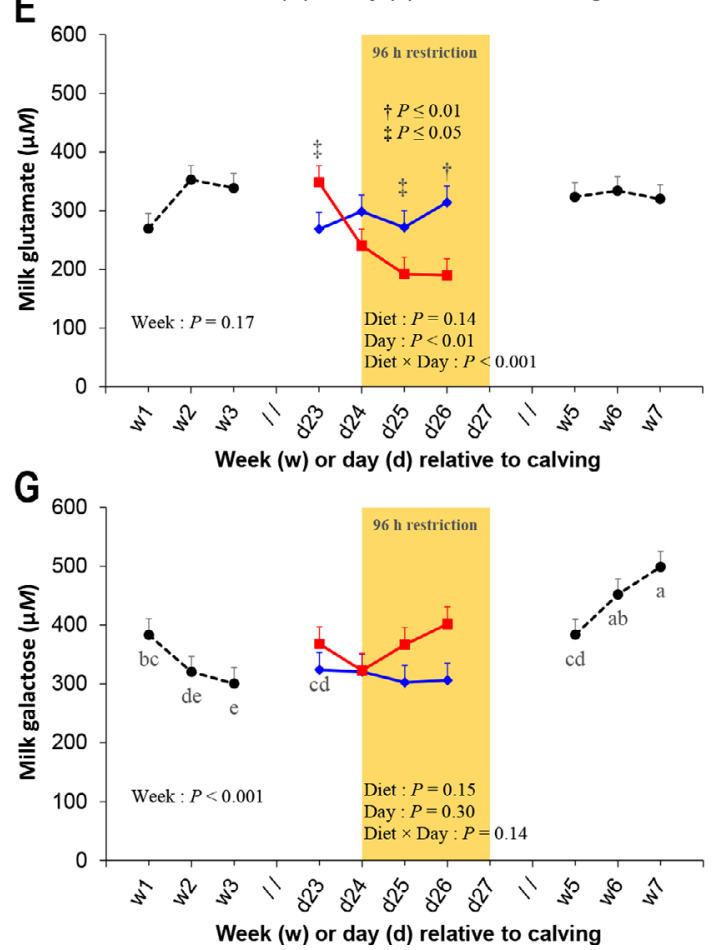

B
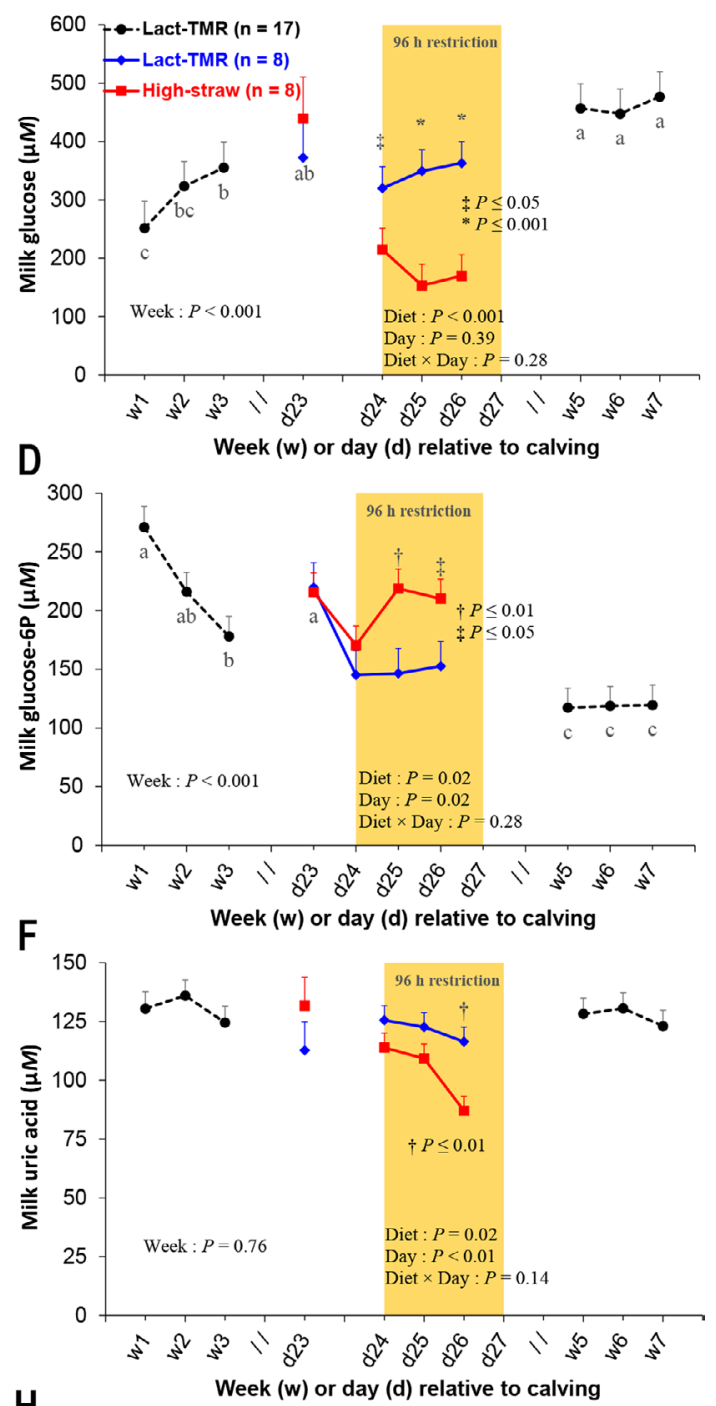

H

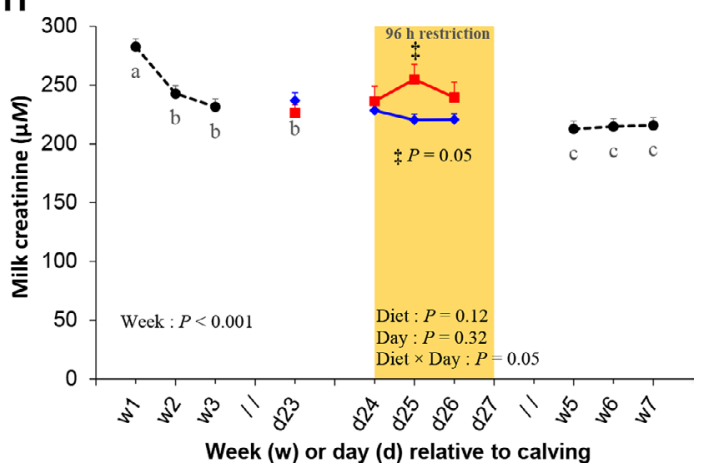

Figure 2. Milk BHB (A), glucose (B), isocitrate (C), and gluclose-6 phosphate (glucose-6P; D), glutamate (E), uric acid (F), galactose (G), and creatinine $(\mathrm{H})$ concentrations in early-lactation multiparous Holstein cows. Cows were studied during the first 7 wk of lactation while allowed ad libitum intake of a lactation TMR (Lact-TMR; $\mathrm{n}=17$ ). A subset of 8 cows underwent $4 \mathrm{~d}$ of nutrient restriction $($ High-straw, $\mathrm{n}=8)$ from 24 to $27 \pm 3$ DIM (mean \pm SD) by receiving a ration composed of $48 \%$ straw (DM basis). Eight cows maintained on the lactation TMR were sampled during the same period to serve as controls. Data were analyzed separately to assess effects of week of lactation (samples collected at $8,15,21,23,35,42$, and $49 \pm 3$ DIM; mean $\pm \mathrm{SD}$ ) and nutritional challenge (samples collected at 23, 24, 25, and $26 \pm 3 \mathrm{DIM}$; mean \pm SD). Values are presented as LSM \pm SEM. Time points not sharing a common letter (a-e) differ in week of lactation data set $(P \leq 0.05)$. Treatment effects at each time point are as follows: $\ddagger P \leq 0.05 ; \dagger P \leq 0.01 ; * P \leq 0.001$. When significant covariates were found for analyses of the challenge data set, data collected at 23 DIM were represented separately as mean and SEM. 
A

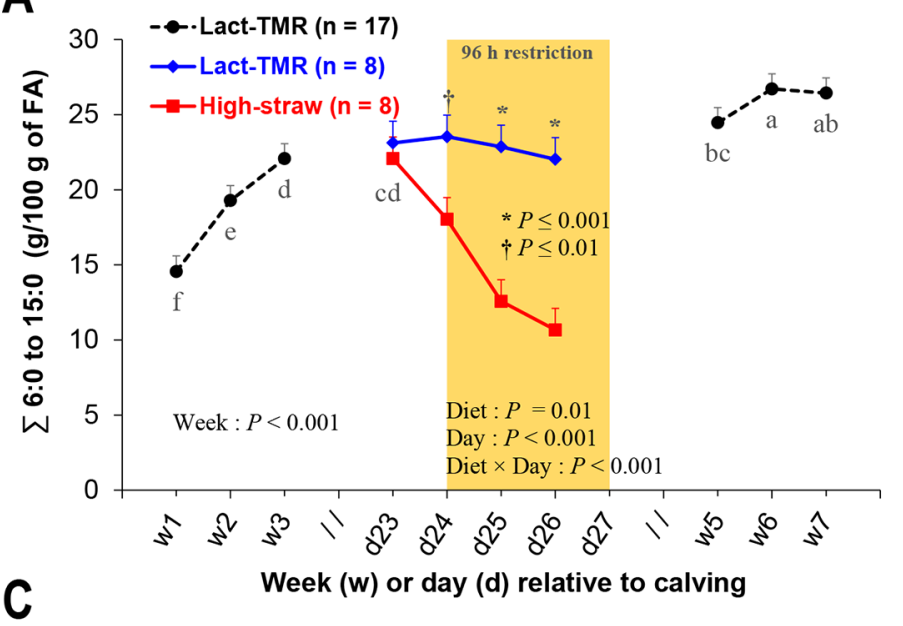

C

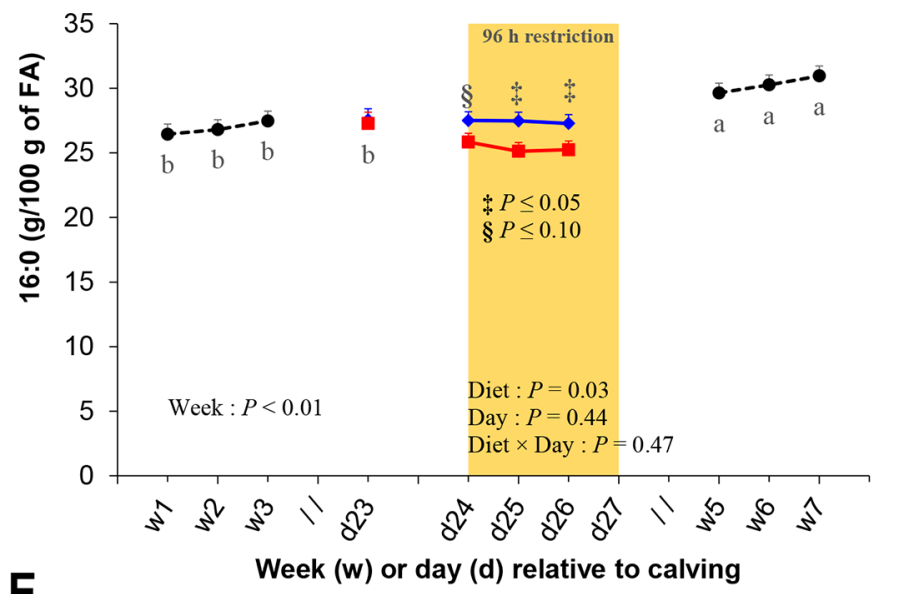

E

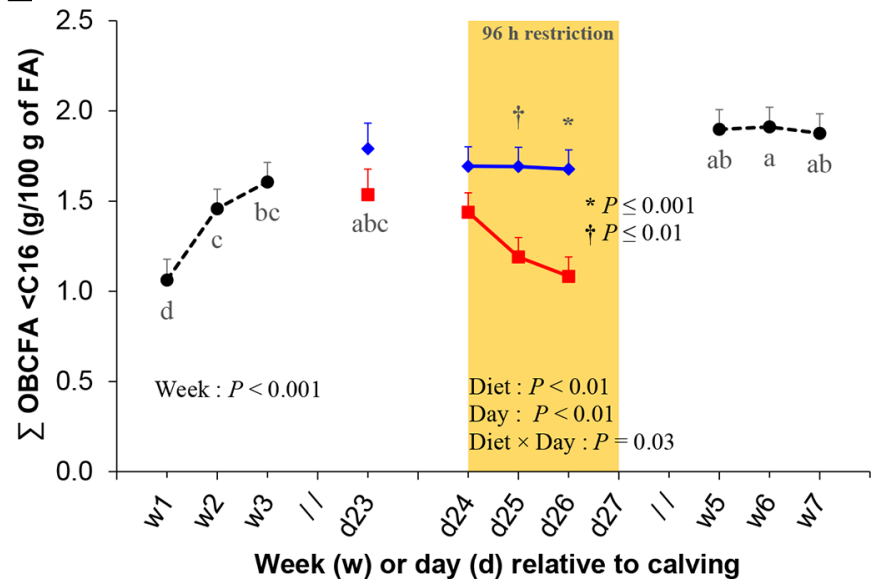

B
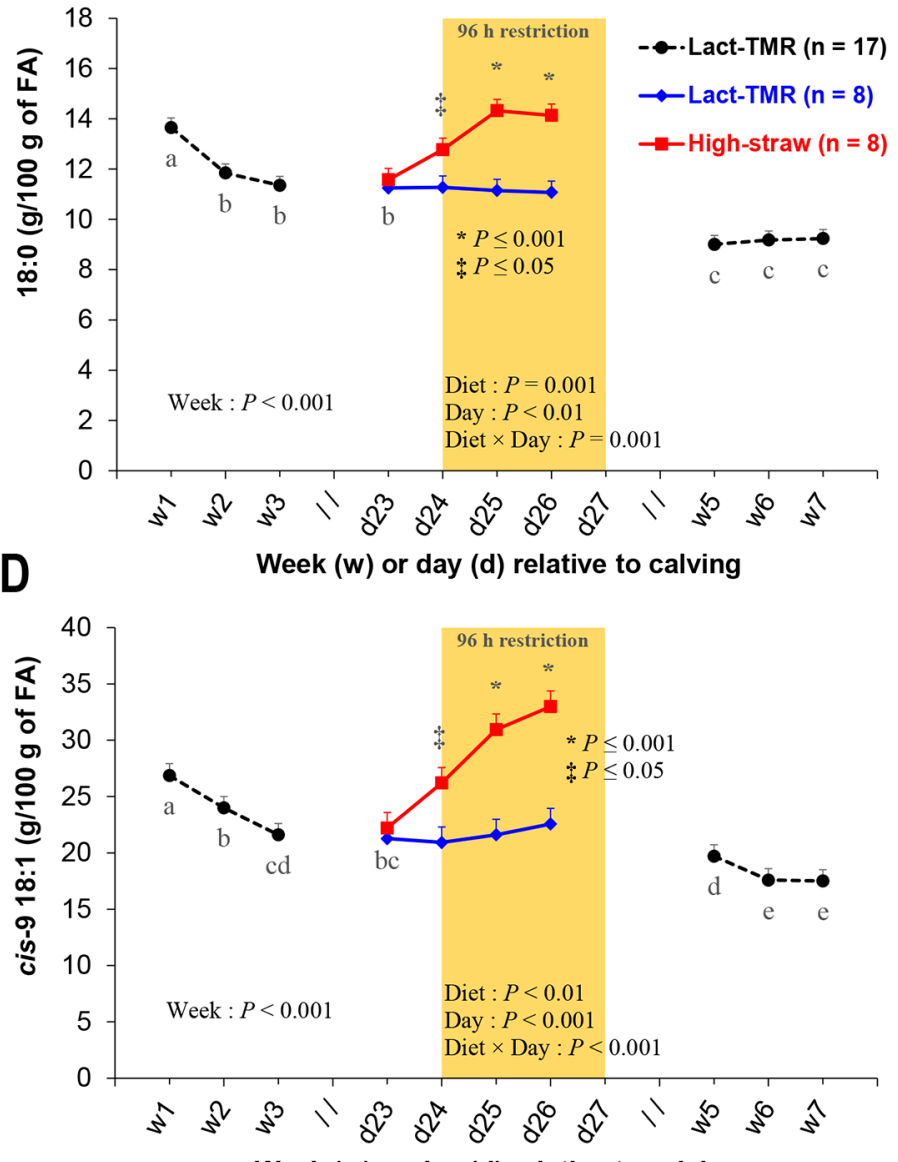

$\mathbf{F}$

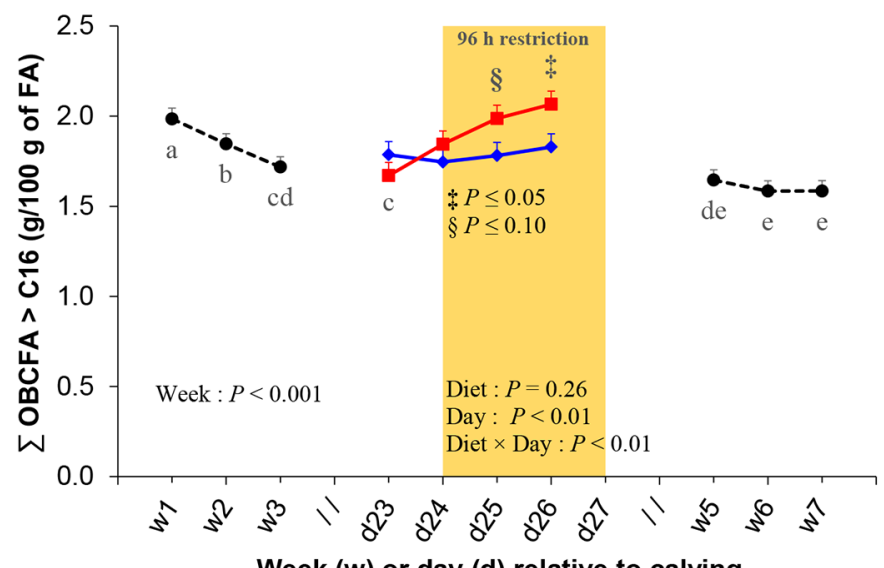

Week (w) or day (d) relative to calving

Figure 3. Milk concentrations of sum of fatty acids (FA) with $\Sigma$ C6:0 to C15:0 (A), C18:0 (B), C16:0 (C), cis-9 C18:1 (D), sum of odd- and branched-chain fatty acids (OBCFA) with carbon chain shorter than $16(\Sigma$ OBCFA $<$ C16; E), and sum of OBCFA with carbon chain greater than 16 ( $\Sigma$ OBCFA $>$ C16; F) in early-lactation multiparous Holstein cows. Cows were studied during the first 7 wk of lactation while allowed ad libitum intake of a lactation TMR (Lact-TMR; $\mathrm{n}=17$ ). A subset of 8 cows underwent $4 \mathrm{~d}$ of nutrient restriction $($ High-straw, $\mathrm{n}=8)$ from 24 to $27 \pm 3$ DIM (mean \pm SD) by receiving a ration composed of $48 \%$ straw (DM basis). Eight cows maintained on the lactation TMR were sampled during the same period to serve as controls. Data were analyzed separately to assess effects of week of lactation (samples collected at $8,15,21,23,35,42$, and $49 \pm 3$ DIM; mean \pm SD) and nutritional challenge (samples collected at 23, 24, 25, and $26 \pm 3$ DIM; mean \pm SD). Values are presented as LSM \pm SEM. Time points not sharing a common letter (a-e) differ in week of lactation data set $(P \leq 0.05)$. Treatment effects at each time point are as follows: $\S P \leq 0.10 ; \ddagger P \leq 0.05 ; \dagger P \leq 0.01 ; * P \leq 0.001$. When significant covariates were found for analyses of the challenge data set, data collected at 23 DIM were represented separately as mean and SEM. 


\section{A Week of Lactation}

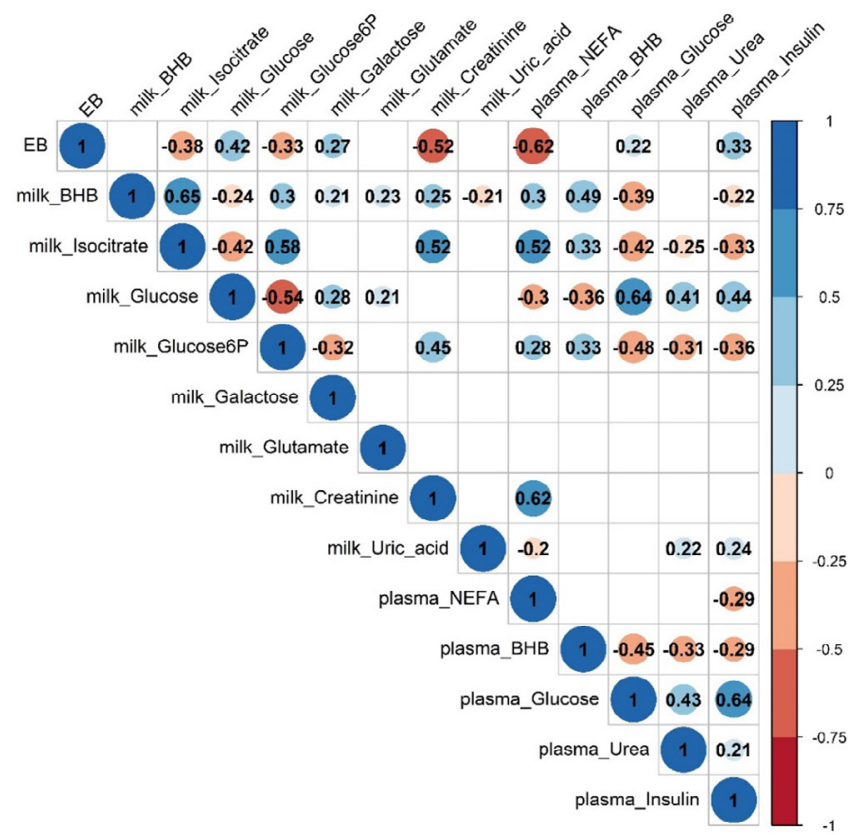

\section{B Challenge Period}

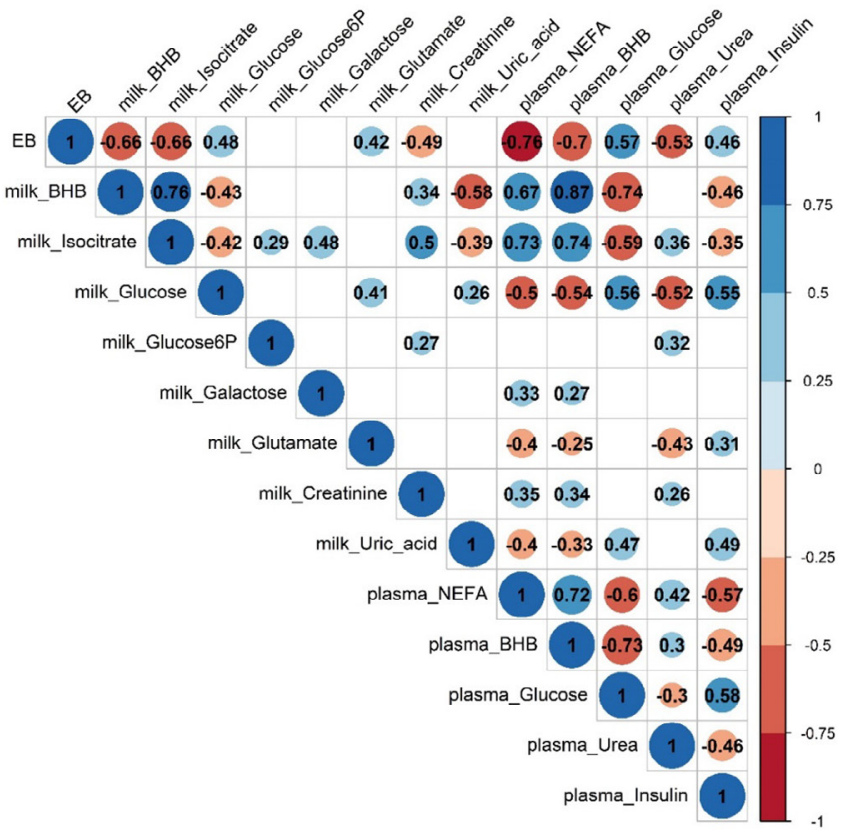

Figure 4. Spearman rank correlations among energy balance, selected milk metabolites, and plasma indicators of metabolic status in early-lactation dairy cows. (A) Week of lactation data set, corresponding to samples collected at $8,15,21,35,42$, and $49 \pm 3$ DIM (mean \pm $\mathrm{SD})$, when cows were allowed ad libitum intake of a lactation TMR (n $=82$ to 84 for correlations with energy balance, and $n=95$ to 99 for correlations among milk and plasma indicators). (B) Challenge-period data set, corresponding to samples collected at 23, 24, 25, and $26 \pm 3$ DIM (mean \pm SD), when 8 cows were restricted by receiving a TMR composed of $48 \%$ straw, whereas 8 cows maintained on the lactation TMR were sampled to serve as controls $(\mathrm{n}=64$ for correlations among energy balance, milk, and plasma indicators). Only significant correlations are presented $(P \leq 0.05)$. NEFA $=$ nonesterified fatty acids; $\mathrm{EB}$ $=$ energy balance; glucose $6 \mathrm{P}=$ glucose -6 phosphate.

\section{A Week of Lactation}

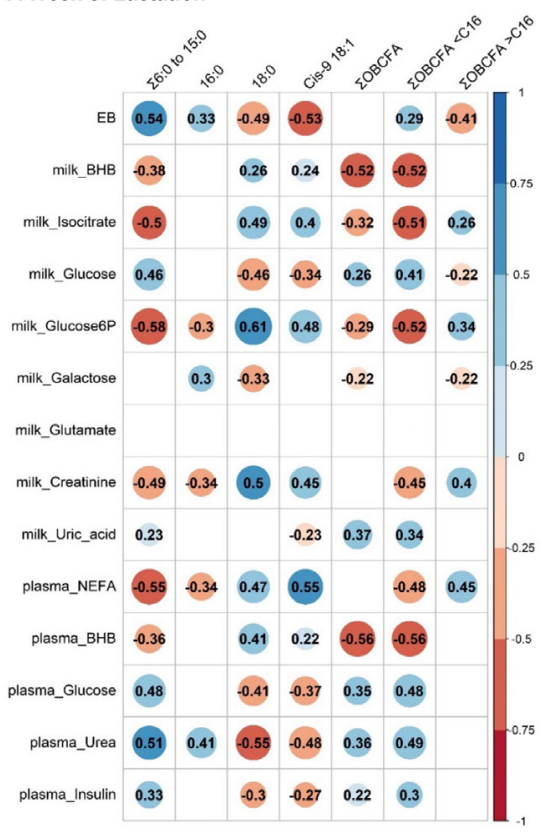

B Challenge Period

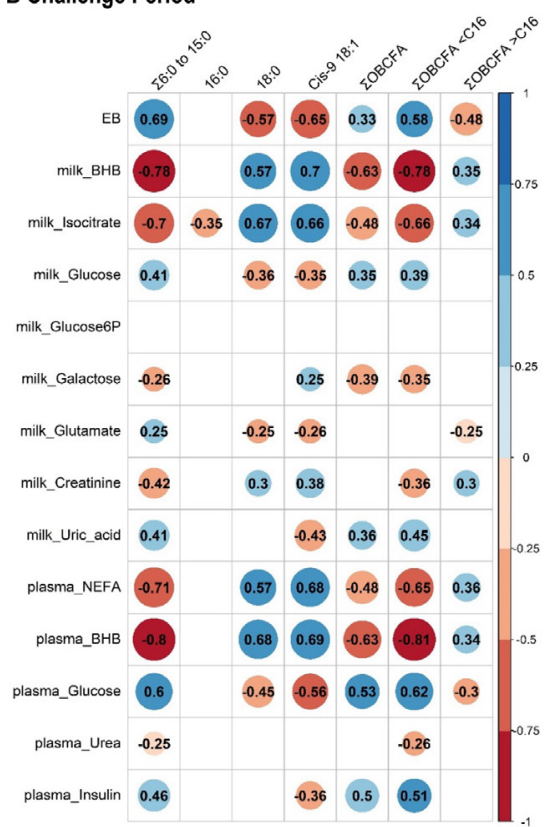

Figure 5. Spearman rank correlations among selected milk fatty acids, energy balance, milk metabolites, and plasma indicators of metabolic status in early-lactation dairy cows. (A) Week of lactation data set, corresponding to samples collected at $8,15,21,35,42$, and $49 \pm 3$ DIM (mean $\pm \mathrm{SD}$ ), when cows were allowed ad libitum intake of a lactation TMR ( $\mathrm{n}=85$ for correlations between FA and energy balance, and $\mathrm{n}=97$ to 99 for correlations among milk FA, milk, and plasma indicators). (B) Challenge-period data set, corresponding to samples collected at $23,24,25$, and $26 \pm 3$ DIM (mean \pm SD), when 8 cows were nutrient-restricted by receiving a TMR composed of $48 \%$ straw, whereas 8 cows maintained on the lactation TMR were sampled to serve as controls $(\mathrm{n}=64$ for correlations among energy balance, milk, and plasma indicators). Only significant correlations are presented $(P$ $\leq 0.05) . \mathrm{NEFA}=$ nonesterified fatty acids; $\mathrm{EB}=$ energy balance; glu$\operatorname{cose} 6 \mathrm{P}=$ glucose- 6 phosphate. 


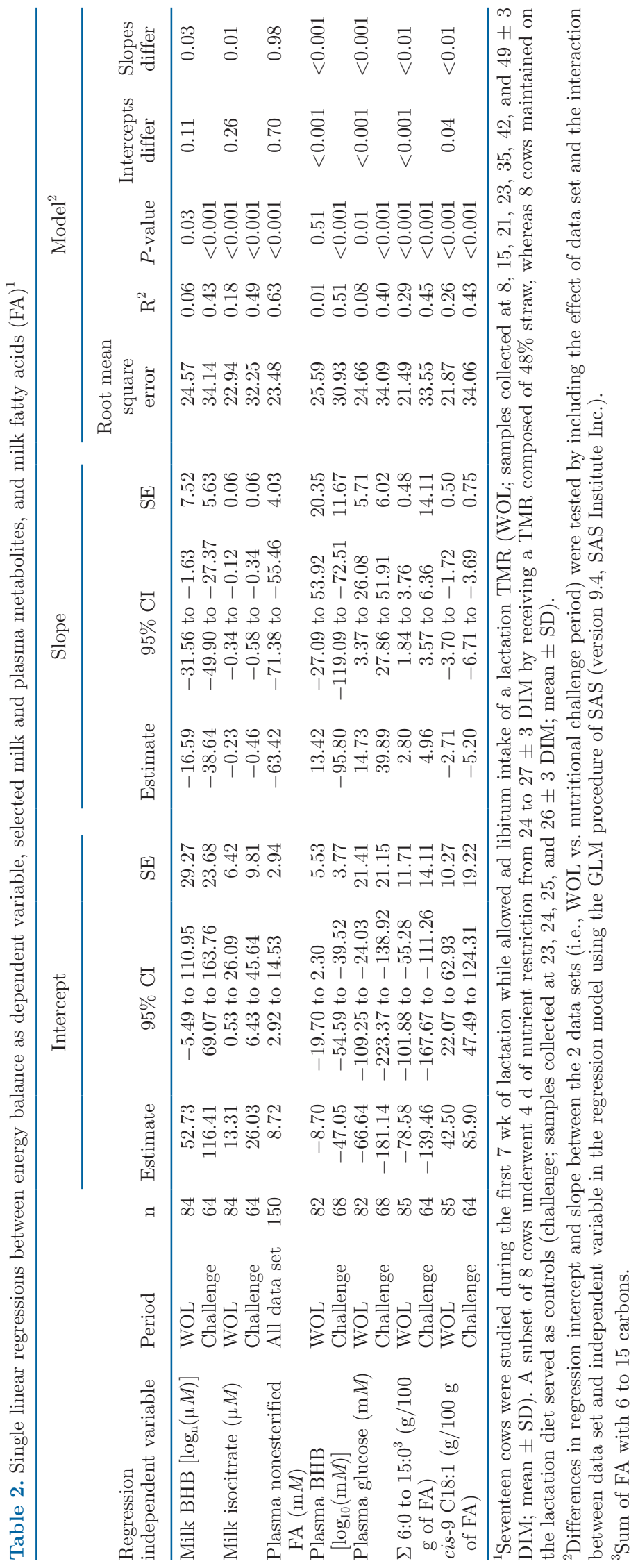


A

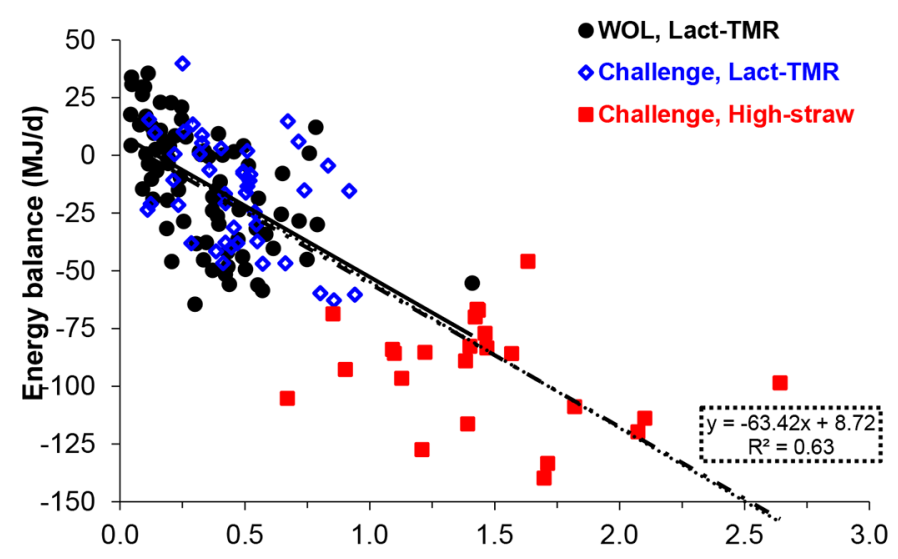

C

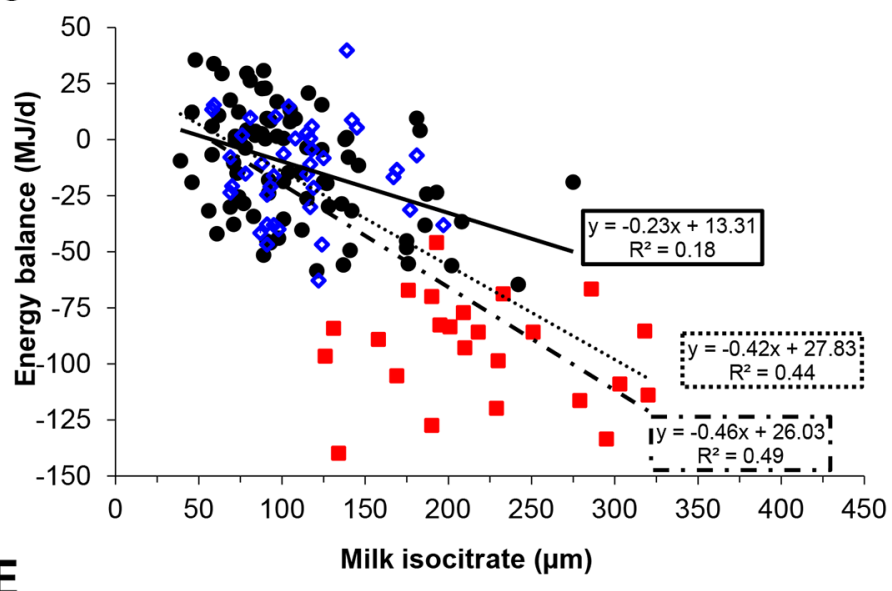

E

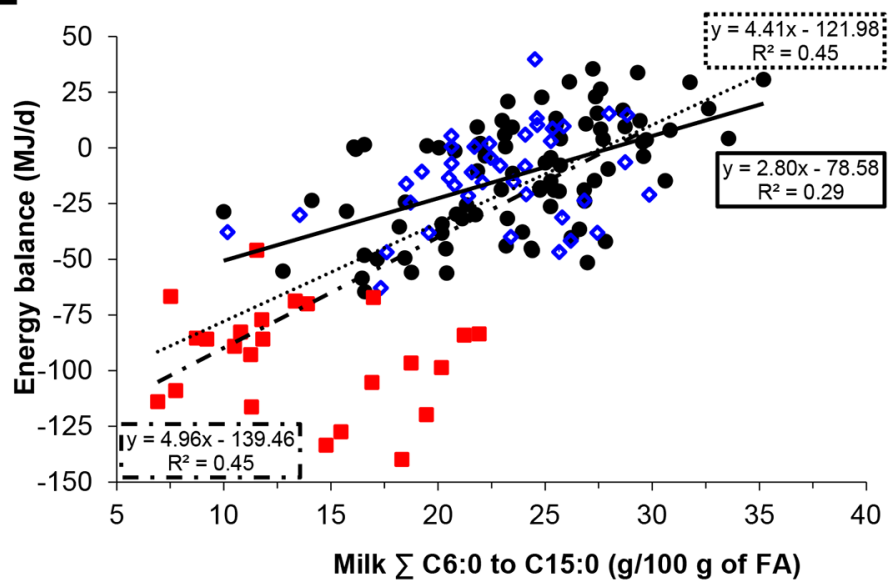

B

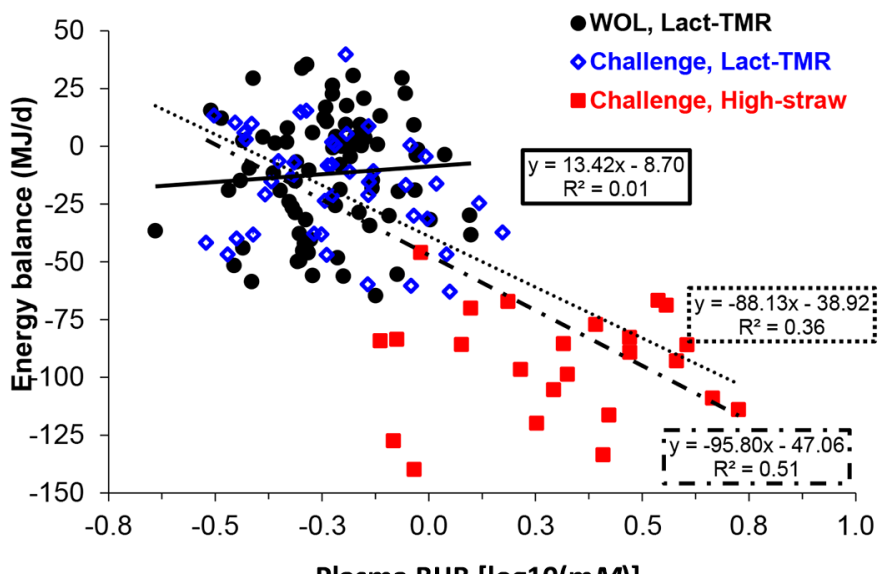

D

Plasma BHB $[\log 10(\mathrm{mM})]$
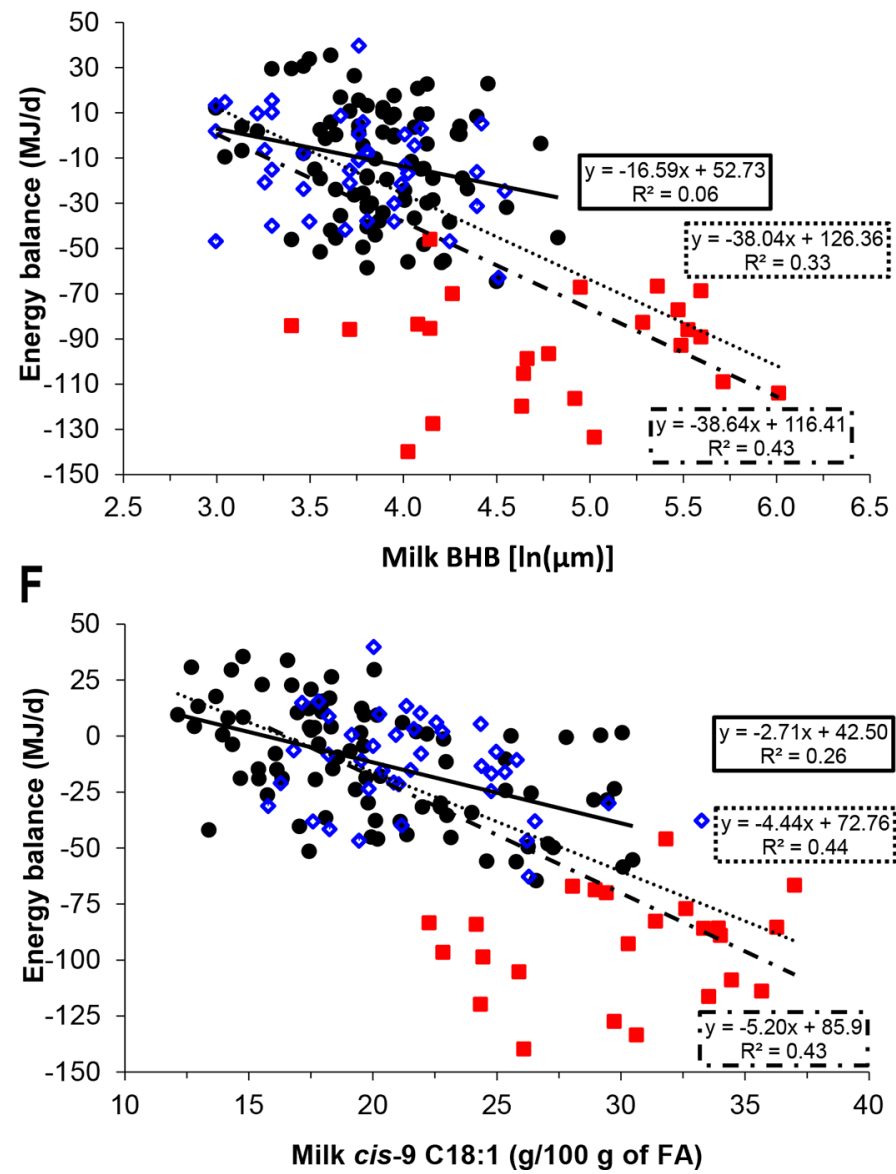

Figure 6. Single linear regressions between energy balance and plasma nonesterified fatty acids (NEFA; A) and plasma BHB (B), milk BHB (C), milk isocitrate (D), milk sum of fatty acids (FA) with 6 to 15 carbons ( $\Sigma$ C6:0 to C15:0; E), and milk cis-9 C18:1 (F) concentrations in early-lactation dairy cows. Regression equations are presented in Table 2. Seventeen cows were studied during the first 7 wk of lactation (WOL) while allowed ad libitum intake of a lactation TMR (- WOL, Lact-TMR; samples collected at 8, 15, 21, 23, 35, 42, and 49 \pm 3 DIM; mean \pm $\mathrm{SD}$ ). A subset of 8 cows underwent $4 \mathrm{~d}$ of nutrient restriction from 24 to $27 \pm 3$ DIM (mean \pm SD) by receiving a ration composed of $48 \%$ straw (ם; Challenge, High-straw; samples collected at 23, 24, 25, and $26 \pm 3$ DIM; mean \pm SD), and 8 cows maintained on the lactation TMR were sampled during the same period to serve as controls ( $\diamond$; Challenge, Lact-TMR). Regression for WOL data (i.e., samples collected at 8 , 15, 21, 23, 35, 42 and $49 \pm 3$ DIM; mean $\pm \mathrm{SD}$ ) is represented with a continuous line (- $(-)$; regression for nutritional challenge period (i.e., samples collected at $23,24,25$, and $26 \pm 3$ DIM; mean $\pm \mathrm{SD})$ using both restricted and control cows is represented with a dash-dot line $(-\cdot-\cdot-\cdot)$; regression using the whole data set is represented with a dotted line (…….....). 


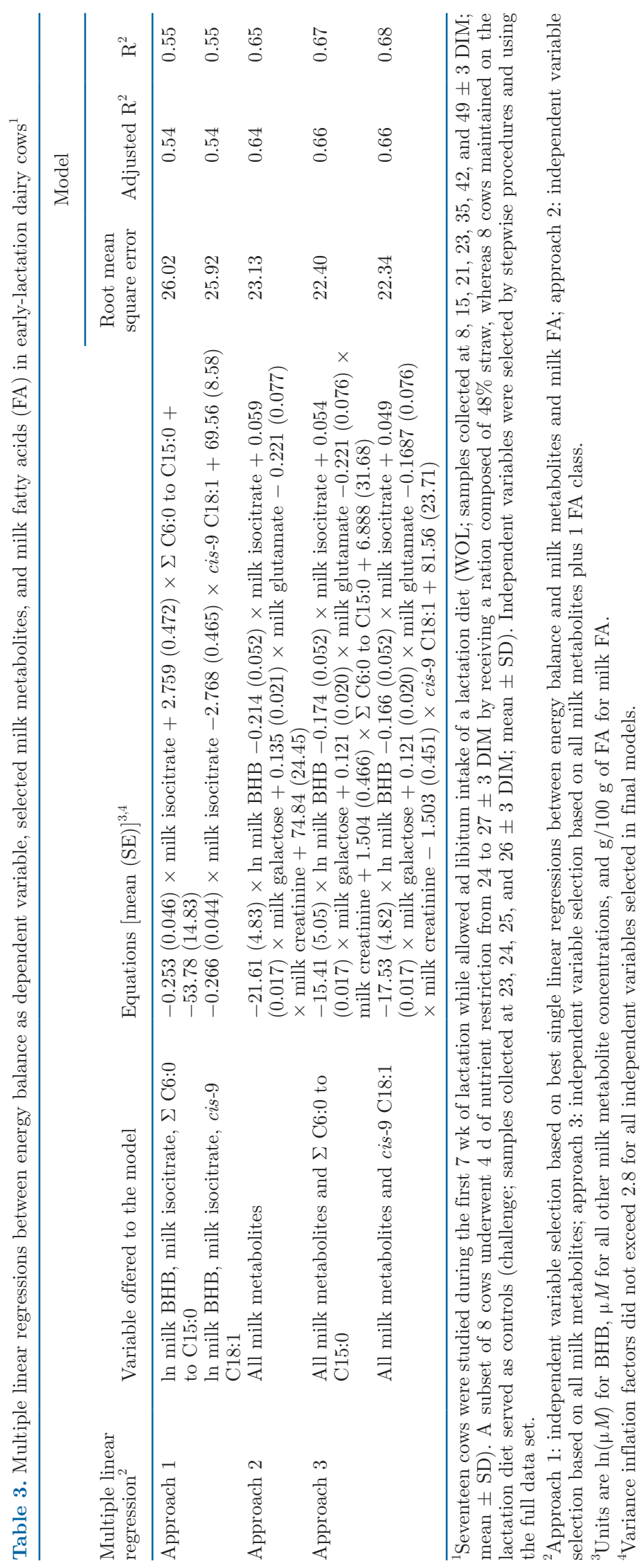


A

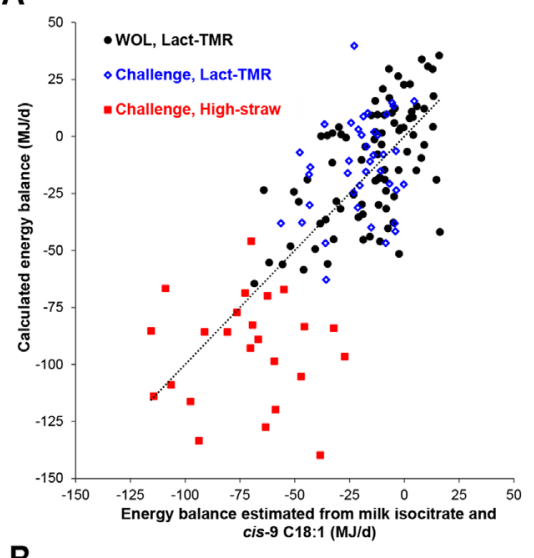

B

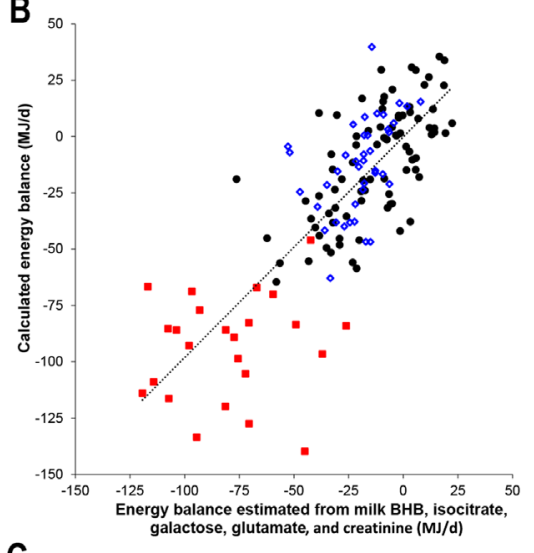

C

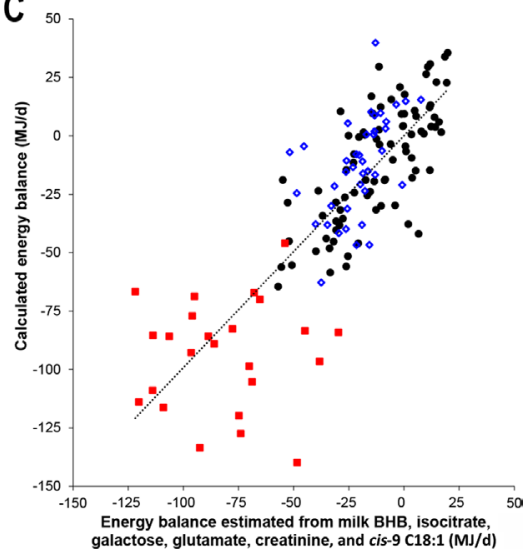

Figure 7. Relationships between calculated energy balance and its estimation from multiple linear regression, using (A) milk isocitrate and milk cis-9 C18:1; (B) ln of milk BHB, milk isocitrate, milk galactose, milk glutamate, and milk creatinine; and (C) ln of milk BHB, milk isocitrate, milk galactose, milk glutamate, milk creatinine, and milk cis-9 C18:1 as dependent variables. Regression equations are presented in Table 3 . Seventeen cows were studied during the first 7 weeks of lactation (WOL) while allowed ad libitum intake of a lactation TMR (-) WOL, Lact-TMR; samples collected at 8, 15, 21, 23, 35,42 , and $49 \pm 3$ DIM; mean $\pm \mathrm{SD}$ ). A subset of 8 cows underwent $4 \mathrm{~d}$ of nutrient restriction from 24 to $27 \pm 3$ DIM (mean \pm SD) by receiving a ration composed of $48 \%$ straw ( $\mathbf{\square}$; Challenge, High-straw; samples collected at 23, 24, 25, and $26 \pm 3$ DIM; mean \pm SD), and 8 cows maintained on the lactation TMR were sampled during the same period to serve as controls ( $\diamond$; Challenge, Lact-TMR). Multiple linear regressions were established using the complete data set by a stepwise procedure. uric acid, and creatinine. The greatest absolute correlations between plasma NEFA and milk metabolites were observed for isocitrate and creatinine $\left(\mathrm{r}_{\mathrm{s}}=-0.52\right.$ and 0.62, respectively; Figure 4A).

In the WOL data set, all reported milk FA were correlated with EB and plasma NEFA, except for $\Sigma \mathrm{OB}$ CFA (Figure 5A). The greatest absolute correlations between FA, EB, and plasma NEFA were observed for $\Sigma$ C6:0 to C15:0 and cis-9 C18:1 $\left(\left|\mathrm{r}_{\mathrm{s}}\right| \geq 0.53\right.$; Figure $5 \mathrm{~A})$. The milk metabolites with the greatest absolute correlations with milk FA were isocitrate, glucose-6P, and creatinine $\left(0.40 \leq\left|\mathrm{r}_{\mathrm{s}}\right| \leq 0.61\right.$ with 3 or more FA; Figure 5A).

Challenge Data Set. Milk glutamate and glucose were positively correlated with EB, whereas milk BHB, isocitrate, and creatinine were negatively correlated with EB during the nutritional challenge period (Figure 4B). Milk BHB and isocitrate showed the greatest absolute correlations with EB $\left(\mathrm{r}_{\mathrm{s}}=-0.66\right)$. No significant correlations with EB were observed for milk glucose-6P, galactose, and uric acid. Milk BHB and glucose were correlated with their respective plasma concentrations $\left(\mathrm{r}_{\mathrm{s}}=0.87\right.$ and 0.56, respectively; Figure 4B).

Plasma BHB and NEFA were correlated with EB during the nutritional challenge period $\left(\mathrm{r}_{\mathrm{s}}=-0.70\right.$ and -0.76 , respectively; Figure 4B). Plasma NEFA was correlated with all milk metabolites except for glucose-6P. The greatest absolute correlations with plasma NEFA were observed for milk BHB and isocitrate among milk metabolites during the nutritional challenge period $\left(\mathrm{r}_{\mathrm{s}}\right.$ $=-0.67$ and 0.73 , respectively; Figure 4B).

During the nutritional challenge period, all reported milk FA were correlated with EB and plasma NEFA, except for C16:0 (Figure 5B). The greatest absolute correlations with EB were observed for $\Sigma$ C6:0 to C15:0 and cis-9 C18:1 $\left(\mathrm{r}_{\mathrm{s}}=0.69\right.$ and -0.65 , respectively; Figure 5B). The milk metabolites with the greatest absolute correlations with milk FA were milk BHB, isocitrate $\left(\left|\mathrm{r}_{\mathrm{s}}\right|>0.60\right.$ with $\left.4 \mathrm{FA}\right)$.

\section{Single and Multiple Linear Regressions}

Single linear regressions between EB and each independent variable (milk metabolites, milk FA, plasma metabolites and insulin) are reported in Table 2 and Supplemental Table S2, https://doi.org/10.5281/ zenodo.5137874 (Pires et al., 2021). Separate regressions are presented for WOL and nutritional challenge when slopes or intercepts were significantly different between the 2 data sets. The intercept and slope of the regression between plasma NEFA and EB were not affected by data set (data set effect: $P=0.70$; data set $\times$ NEFA interaction: $P=0.98)$, and the regression $\mathrm{R}^{2}$ was 0.63 when using the whole data set (Table 
2; Figure 6A). Plasma BHB, plasma glucose, milk BHB, milk isocitrate, milk $\Sigma$ C6:0 to C15:0, and cis-9 C18:1 showed the best $\mathrm{R}^{2}$ for single linear regressions with EB during the nutritional challenge period $\left(R^{2} \geq\right.$ 0.40; Table 2; Figure 6 and Supplemental Figure S3, https://doi.org/10.5281/zenodo.5137874; Pires et al., 2021). Concerning the WOL data set, the regressions between EB and plasma BHB, milk BHB, and plasma glucose were either not significant or very poor $\left(\mathrm{R}^{2} \leq\right.$ 0.08; Table 2; Figures 6B, 6D and Supplemental Figure S3; Pires et al., 2021). We explored single linear regressions between plasma NEFA as dependent variable and each milk metabolite measured in this study. The best regressions with plasma NEFA for which the intercept and slope was not affected by the sampling period (i.e., WOL vs. nutritional challenge) were observed for milk isocitrate $\left(\mathrm{R}^{2}=0.39\right), \Sigma \mathrm{C} 6: 0$ to $\mathrm{C} 15: 0$ $\left(\mathrm{R}^{2}=0.45\right)$ and cis-9 $\mathrm{C} 18: 1\left(\mathrm{R}^{2}=0.45\right.$; Supplemental Figure S4, https://doi.org/10.5281/zenodo.5137874; Pires et al., 2021).

Multiple linear regressions between EB and concentrations of metabolites and FA in milk were explored using the whole data set and are presented in Table 3 and Figure 7. Milk isocitrate and a milk FA class were selected as explanatory variables in the multiple linear regression when milk $\mathrm{BHB}$, milk isocitrate, and 1 milk FA class were initially offered to the model (adjusted $\mathrm{R}^{2}$ $=0.54$, approach 1). Milk BHB, isocitrate, galactose, glutamate, and creatinine were significant when all milk metabolites were initially offered to the multiple linear regression model (adjusted $\mathrm{R}^{2}=0.64$; approach 2 ). The same milk metabolites were significant when all milk metabolites plus a FA class were initially offered to the model (adjusted $\mathrm{R}^{2}=0.66$; approach 3 ). Variance of residuals was significantly greater in highstraw compared with Lact-TMR for single regressions between EB and milk BHB, $\Sigma$ C6:0 to C15:0, cis-9 C18:1, plasma NEFA, and for all multiple regression models reported.

\section{DISCUSSION}

We studied the effects of 2 complementary models of metabolic imbalance (i.e.; physiological early lactation and induced undernutrition) on milk metabolite and FA concentrations in early-lactation dairy cows. We assessed the relationships among different putative milk biomarkers of metabolic status and EB by correlation analyses, and we focused on the associations between $\mathrm{EB}$, milk metabolites and FA using single linear regressions. We further explored the potential of milk metabolites and FA to explain the EB variation observed in this study by multiple linear regression.

\section{Effect of p.m. and a.m. Milkings}

Hour and time of sampling relative to TMR distribution are variation factors for plasma metabolite concentrations such as glucose, NEFA, and BHB (Allen, 2014; Piantoni et al., 2015; Seely et al., 2021). In the current study, concentrations of milk metabolites differed between p.m. and a.m. milkings, except for isocitrate, galactose, and creatinine. Furthermore, regressions between a.m. and p.m. milkings were poor for milk BHB and glucose concentrations. Previous research with cows milked by a robotic system showed time of milking effects for milk BHB, glucose, and uric acid, as observed in our study, but not for milk glucose-6P concentrations (Larsen et al., 2016). Unequal betweenmilking intervals may have played a role in p.m. and a.m. differences observed for milk metabolite concentrations in this study ( 7 vs. $17 \mathrm{~h}$ between milkings, respectively). Standard milk sampling conditions need to be established for milk metabolites to be used as indicators of metabolic status. Further research is warranted to test the effects of different milking intervals, from once a day milking to multiple milkings per day using robotic systems, which would constitute extremes of milking frequency.

For the comparison of p.m. and a.m. milkings, we did not include data collected when cows received the highstraw (i.e., 8 cows from d 1-3 of nutritional challenge). Nutritional challenges induce rapid metabolic changes (Pires et al., 2019), and comparisons between p.m. and a.m. milkings would be confounded by differences in time elapsed from initiation of nutrient restriction and milk sampling (p.m. milk samples were collected approximately at 7,31 , and $55 \mathrm{~h}$, whereas a.m. milk and plasma samples were collected at 24,48 , and $72 \mathrm{~h}$ relative to initiation of high-straw TMR). For this reason, and because plasma samples were collected after a.m. milkings, all further data analyses were performed using a.m. milk metabolite concentration data.

\section{Longitudinal Data and Correlations}

The high-straw TMR induced negative EB (-109 to $-87 \pm 7 \mathrm{MJ} / \mathrm{d}$ ), lipomobilization, and metabolic imbalance, including high plasma NEFA and BHB, and low plasma glucose. During the nutritional challenge period, EB was lower, and plasma NEFA and BHB concentrations were greater than observed during early lactation in our experiment. These results are in agreement with previous research involving early-, mid- and late-lactation cows that were offered a TMR containing $60 \%$ straw (Bjerre-Harpøth et al., 2012), and showing that metabolic responses to nutrient restriction models 
are enhanced during early lactation compared with later lactation stages, particularly for plasma BHB and glucose (Bjerre-Harpøth et al., 2012).

The responses of milk concentrations of $\mathrm{BHB}$, isocitrate, glucose, glucose-6P, and creatinine were concordant during early lactation (a period of spontaneous negative EB) and during the nutritional challenge induced by feeding the high-straw TMR. Milk glucose and glucose-6P responses were in agreement with previous research in early-lactation cows, showing a gradual increase in milk glucose and a decrease in glucose-6P with DIM (Larsen and Moyes, 2015; Zachut et al., 2016). Milk galactose and creatinine were modulated by WOL. Plasma creatinine concentrations decrease during early lactation due to protein mobilization and loss of muscle mass (Pires et al., 2013; Megahed et al., 2019). Therefore, the time effect observed for milk creatinine in WOL data set may reflect plasma creatinine variations typical for early lactation. Our results are concordant with a previous study that showed a decrease in milk creatinine during the first $8 \mathrm{wk}$ of lactation, and positive correlations between milk creatinine, plasma creatinine, and 3-methyl-hystidine $(0.41 \leq \mathrm{r} \leq$ 0.59 ), which are plasma indicators of muscle mobilization (Larsen et al., 2017). Milk creatinine was negatively correlated with EB in both WOL and nutritional challenge data set $\left(\mathrm{r}_{\mathrm{s}}=-0.52\right.$ and -0.49 , respectively), as reported for dairy cows in wk 2 of lactation (Xu et al., 2020b). Milk glutamate and uric acid concentrations responded only to nutritional challenge and were not modulated by WOL. Milk glutamate was positively correlated with EB during the nutritional challenge period, as observed in mid-lactation feed-restricted cows (Billa et al., 2020), but not during early lactation in the current study. No significant correlations were observed between uric acid and $\mathrm{EB}$ in the current study. Xu et al. (2018) found negative correlations between EB and isocitrate and creatinine in wk 2 of lactation, when cows were in physiological negative EB, but correlations disappeared or became weak in wk 7 of lactation, when cows were in positive EB. Furthermore, correlations between EB and milk glutamate were negative on wk 2 of lactation (Xu et al., 2018, 2020a,b), in contrast with the current study. In our study, we observed marginal evidence for a positive correlation in the WOL data set $\left(\mathrm{r}_{\mathrm{s}}=0.20 ; P=0.06\right)$ and a significant positive correlation in the nutritional challenge data set, as in a previous feed-restriction study (Billa et al., 2020). Milk NAGase activity, an indicator of udder inflammation, was modulated by DIM, decreasing as lactation progressed (Supplemental Figure S1, https://doi.org/10 .5281 /zenodo.5137874; Pires et al., 2021), but was not correlated with EB in either WOL or nutritional chal- lenge data sets. Concentration of NAGase was greatest on wk 1 of lactation, for which we do not have EB data.

Milk and plasma BHB and plasma glucose are classic indicators of ketosis and metabolic status (Overton et al., 2017). Milk BHB and glucose were positively correlated with their plasma concentrations in both WOL ( $\mathrm{r}_{\mathrm{s}}=0.49$ and 0.64 , respectively) and challenge ( $\mathrm{rs}=0.87$ and 0.56 , respectively) data sets. Previous studies report correlations between milk and plasma BHB ranging from 0.66 to 0.90 in early-lactation cows (Enjalbert et al., 2001; Nielsen et al., 2003; Xu et al., 2020b). There is limited literature comparing glucose concentrations in plasma and milk. Glucose is a limiting nutrient for dairy ruminants, and the decrease in milk glucose concentrations observed during undernutrition may be a consequence of limiting availability for mammary uptake from blood (Chaiyabutr et al., 1981). We found a correlation of 0.61 between milk and plasma glucose concentrations in feed-restricted mid-lactation cows (Billa et al., 2020), which is close to the correlations in the current study. Therefore, glucose and BHB concentrations in milk partially reflect their plasma concentrations. Milk metabolite concentrations probably integrate variations of plasma concentrations occurring during the period between 2 consecutive milkings, whereas plasma concentrations are measured at single time point. Therefore, circadian variations in plasma glucose and BHB concentrations, feed distribution, and milking time (e.g.; a.m., p.m., multiple daily milkings with robotic systems) will affect correlations between plasma and milk, and may interfere with the detection of borderline hyperketonemic cows (Nielsen et al., 2003; Seely et al., 2021). Sampling site may affect plasma metabolite concentrations. Glucose concentrations were $3.2 \%$ lower in plasma collected from jugular compared with coccygeal veins (Gelfert and Staufenbiel, 1998). Others report no differences in glucose concentration between jugular and coccygeal veins, but observed a $2.1 \%$ lower glucose concentration in plasma collected from the coccygeal vein compared with coccygeal artery (Parker and Blowey, 1974). Whole blood BHB concentrations did not differ between jugular and coccygeal samples (Mahrt et al., 2014). We collected blood from jugular veins to study nutritional challenge effects, and from the coccygeal vein or artery for other time points. We observed a significant increase in plasma glucose between 21 DIM (coccygeal sampling) and 23 DIM (jugular sampling), and we expect sampling site effects to be minor compared with DIM and diet effects.

Milk content in preformed FA increases during periods of nutritional deficit and lipomobilization, with concomitant decrease in FA synthesized de novo by the mammary gland. The high-straw TMR induced 
modifications of milk FA profiles that mimicked those observed during the first 3 wk of lactation, including increased concentrations of potentially mobilized FA (e.g., C18:0 and cis-9 C18:1), and decreased concentrations of FA synthesized de novo (e.g., $\Sigma$ C6:0 to C15:0), as previously observed in underfed mid-lactation cows (Gross et al., 2011a; Billa et al., 2020). Milk 4:0 was not correlated with $\mathrm{EB}$, and it was not included in the class of short- and medium-chain FA ( $\Sigma$ C6:0 to C15:0). Milk $\Sigma$ C6:0 to C15:0, C18:0, and cis-9 C18:1 in both WOL and challenge data sets were correlated with EB; plasma NEFA, BHB, and glucose; and milk isocitrate, glucose, and creatinine. We observed a significant but small diet effect for C16:0 and marginal evidence of a diet by time interaction for $\Sigma$ OBCFA, which probably reflected the double origin of these FA, because they are partially preformed and partially synthesized de novo by the mammary gland (Chilliard et al., 2000; Vlaeminck et al., 2015). Accordingly, C16:0 and $\Sigma$ OBCFA were either not correlated or had relatively low correlations with EB and plasma NEFA. Milk concentrations of $\Sigma$ OBCFA $>$ C16 increased and $\Sigma$ OBCFA $<$ C16 decreased during early lactation and in response to the nutritional challenge, and both FA classes showed opposite correlations with EB and plasma NEFA, as observed previously in feed-restricted mid-lactation cows (Billa et al., 2020). Therefore, OBCFA should not be considered a homogeneous FA class when investigating links with body reserve mobilization. The mammary gland can synthesize C15:0 and C17:0 de novo, and some elongation of branched-chain FA has been shown to occur postruminally (Vlaeminck et al., 2015). The observed variations in milk $\Sigma$ OBCFA $<$ C16 probably reflected modifications of ruminal synthesis, incorporation into milk fat, and de novo synthesis by the mammary gland, whereas $\Sigma$ OBCFA $>$ C16 is associated with mobilization of body fat.

Downregulation of de novo FA synthesis during periods of undernutrition may decrease NADPH requirements of the mammary epithelial cells. Because the majority of the NADPH required for mammary lipogenesis in ruminants is generated from the decarboxylation of isocitrate (Bell and Bauman, 1997), downregulation of this pathway would explain the increase in milk isocitrate concentrations (Chaiyabutr et al., 1981; Billa et al., 2020). Diet-induced milk fat depression was also associated with increased milk isocitrate concentrations in Holstein cows (Bernard et al., 2020), again linking mammary lipogenesis and milk isocitrate concentrations. Zachut et al. (2016) suggested that increased milk glucose-6P concentrations observed during early lactation may be due to activation of pentose phosphate pathway in mammary epithelial cells. It would allow NADPH requirements to be met for mitigation cellular oxidative stress during periods of increased FA oxidation. We found no correlations of milk glucose-6P with EB, plasma NEFA, and BHB during the nutritional challenge period, despite induction of subclinical ketosis and intense lipomobilization in cows receiving high-straw treatment. For unknown reasons, milk glucose-6P concentration increased significantly between 21 and $23 \operatorname{DIM}(P=0.03)$, before nutritional challenge was initiated, which may have affected associations with other indicators of metabolic status in the current study. For instance, correlation between glucose-6P and $\mathrm{EB}$ was $0.37(P<0.01)$ in the challenge data set when excluding data collected at 23 DIM.

\section{Single and Multiple Linear Regressions}

Single linear regressions between EB and independent variables were initially explored using both data sets (i.e., WOL and nutritional challenge period) to test for differences in regression intercepts and slopes because data range and correlations with EB differed between data sets. Fitness of regression models were assessed by residual plot analyses and $\mathrm{R}^{2}$ because we focused on the associations between different putative biomarkers and EB, not on predictive ability, given the small data set and the use of an experimental nutrient restriction model. In this study, plasma NEFA presented the best single linear regression with EB among all indicators studied $\left(\mathrm{R}^{2}=0.62\right)$; furthermore, the regression intercept and slope did not differ between data sets. These results are in agreement with earlier reports on the relationships between EB and plasma NEFA concentrations (Doreau, 1983). Nonetheless, associations between plasma NEFA and EB may vary depending on sampling protocol and husbandry conditions. For instance, plasma NEFA concentrations present diurnal variations and decrease within minutes after TMR distribution and feed intake (Nielsen et al., 2003; Allen, 2014; Piantoni et al., 2015). Other studies reported weak or no correlations between plasma NEFA and EB (McNamara et al., 2003; Wylie et al., 2008). Cows under high-straw TMR became subclinically ketotic, with inherent changes in plasma glucose and BHB concentrations. Single linear regressions between $\mathrm{EB}$ and plasma glucose and BHB had a lower $\mathrm{R}^{2}$ than observed for plasma NEFA during the nutritional challenge period (0.51 and 0.40, respectively), but regressions were meaningless $\left(\mathrm{R}^{2} \leq 0.08\right)$ for the WOL data set. Plasma glucose is under tight regulation by insulin and other hormones (Bell and Bauman, 1997); both glucose and insulin are used in research as indicators of metabolic status, but glucose homeostatic regulations probably modulate the associations between glucose and EB. Nonetheless, regression $\mathrm{R}^{2}$ was 0.30 and 36 
for plasma glucose and BHB, respectively, when all the data were pooled (Figure 6B and Supplemental Figure S3, https://doi.org/10.5281/zenodo.5137874; Pires et al., 2021). This is explained by the greater range of metabolic deviations observed in response to nutrient restriction compared with the spontaneous negative $\mathrm{EB}$ observed in this study. Milk isocitrate single linear regression with $\mathrm{EB}$ showed the greatest $\mathrm{R}^{2}$ among all the milk metabolites studied, despite significant slope differences between the 2 data sets. These results contrast with a previous study involving mid-lactation cows that identified milk glucose and glutamate, not isocitrate, as the most promising indicators of $\mathrm{EB}$ in response to 6 $\mathrm{d}$ of partial feed restriction (Billa et al., 2020). In the current study, regressions between EB, milk glucose, and glutamate had low $R^{2}(\leq 0.20)$. Single linear regressions between EB and milk $\Sigma$ C6:0 to C15:0 and cis-9 C18:1 showed significant intercept and slope differences between the 2 data sets, but the $\mathrm{R}^{2}$ were among the highest for both WOL and challenge data sets, compared with other milk indicators studied.

Because EB calculations involve a certain degree of uncertainty (Thorup et al., 2012) and may be overestimated during early lactation (Erdmann et al., 2019), we further explored single linear regressions between plasma NEFA, used as a systemic indicator of lipomobilization, and milk metabolite and FA concentrations. Milk isocitrate $\left(\mathrm{R}^{2}=0.39\right), \Sigma \mathrm{C} 6: 0$ to $\mathrm{C} 15: 0\left(\mathrm{R}^{2}=\right.$ $0.45)$, and cis-9 $\mathrm{C} 18: 1\left(\mathrm{R}^{2}=0.45\right)$ had the best single linear regressions with plasma NEFA. Furthermore, regression intercepts and slopes were not affected by the data set (i.e., WOL vs nutritional challenge period). These single linear regressions between milk FA and plasma NEFA have $R^{2}$ similar to previous reports $\left(R^{2}\right.$ $=0.38$ to 0.42; Jorjong et al., 2014; Dórea et al., 2017). Milk cis-9 C18:1 concentration, and ratios of cis-9 C18:1 with various FA synthesized de novo, have been proposed as indicators of excessive lipomobilization and hyperketonemia in early-lactation cows (Jorjong et al., 2014, 2015; Dórea et al., 2017).

Multiple linear regressions between EB and concentrations of milk metabolites and milk FA were explored using the whole data set (i.e., pooled WOL and nutritional challenge data sets) to determine the panel of milk metabolites and FA associated with a wide range of EB. For parsimony, we started by offering milk BHB, milk isocitrate, and 1 milk FA variable to the regression models because these variables had the best single linear regressions with EB (approach 1; Table 3). Multiple linear regressions that included milk isocitrate and 1 milk FA as predictors of EB had an adjusted (adj)$\mathrm{R}^{2}$ of 0.54 , which is a slight improvement compared with single linear regressions using the whole data set between EB and isocitrate alone $\left(\mathrm{R}^{2}=0.44\right)$. The mul- tiple linear regression improved when it included milk $\mathrm{BHB}$, isocitrate, galactose, glutamate, and creatinine, which were significant explanatory variables when all milk metabolites were initially offered to the model $\left(\operatorname{adj}-R^{2}=0.64 ;\right.$ approach 2$)$. Additional inclusion of a milk FA class had a small effect on regression (adj$\mathrm{R}^{2}=0.66$; approach 3 ). Among the milk metabolites selected by the stepwise procedure, some were correlated with EB independently of the data set (isocitrate, creatinine, and FA), some were correlated with $\mathrm{EB}$ in the nutritional challenge data set only (milk BHB and milk glutamate), or some were correlated with EB in the WOL data set only (galactose). Per design, highstraw TMR induced large absolute EB values compared with EB observed for Lact-TMR. In the challenge data set, variance of residuals was significantly greater in high-straw compared with Lact-TMR for single regressions between EB and milk BHB, $\Sigma$ C6:0 to C15:0, cis-9 C18:1, and plasma NEFA. In multiple regression, variance of residuals is greater for high-straw compared with Lact-TMR for all models reported. Unequal variance between treatments was modeled in repeated measures analyses, but this was not possible with the regression analyses used.

This research shows that selected milk metabolites are promising biomarkers of EB and metabolic status. Milk sampling is noninvasive, easy to perform, minimizes animal handling, and is well adapted to grazing dairy systems and behavioral research, as it does not require additional animal handling that might affect time budgets and induce stress. Repeated sampling is required to study metabolic adaptations of earlylactation cows, which may not be practical for on-farm monitoring of metabolic disorders at the individual level. A variety of phenotypes important for the dairy industry can be predicted by milk Fourier transform mid-infrared spectrometry (FT-MIR), including milk FA composition, milk acetone, BHB and citrate concentrations, plasma indicators of metabolic status, and EB (Grelet et al., 2016; Pralle and White, 2020). Foldager et al. (2020) investigated the use of milk FT-MIR and a set of milk metabolites (BHB, glucose, glucose 6-P, isocitrate, urea, uric acid) plus 2 enzymes to predict EB and clusters physiologically unbalanced cows. They suggest milk FT-MIR as a more practical alternative to laboratory quantification of selected milk metabolites. The advantages and limitations of milk FT-MIR technology to estimate milk BHB and monitor hyperketonemia were reviewed elsewhere (Pralle and White, 2020) and may share communalities with other milk metabolites. The relatively low sensitivity to detect subclinical ketosis, technical and proprietary issues related to FT-MIR predictions, and sampling frequency (often once monthly) are weighed against 
the high-throughput, low-cost phenotyping afforded by FT-MIR.

This was an exploratory study involving a limited number of early-lactation cows in a wide range of $\mathrm{EB}$ and metabolic status, which included subclinical ketosis induction by experimental nutrient restriction. Per design, diet was causal of low EB, residual variance was significantly greater for high-straw than Lact-TMR in most models, and certain associations with EB may be confounded with diet effects. Single and multiple regressions used do not model repeated cow sampling. Regressions were not validated by an external data set and may not be generalizable. Regressions are presented to illustrate the potential of milk metabolites and FA as noninvasive biomarkers of energy status of dairy cows.

\section{CONCLUSIONS}

Metabolites secreted in milk may serve as noninvasive indicators of metabolic status and EB of early-lactation cows. Modifications of milk BHB, isocitrate, glucose, glucose-6P, and creatinine were concordant in early lactation and during the nutritional challenge, whereas milk glutamate and uric acid responded only to the nutritional challenge, and milk galactose was modulated only by DIM. Milk isocitrate concentrations did not differ between p.m. and a.m. milkings, and presented the best associations with EB and indicators of lipomobilization such as plasma NEFA and milk FA among milk metabolites studied. Multiple linear regression including milk $\mathrm{BHB}$, isocitrate, galactose, glutamate, and creatinine explained up to $64 \%$ of the EB variation observed in the current study when pooling WOL and challenge data sets. Milk $\Sigma$ C6:0 to C15:0, C18:0, and cis-9 C18:1 were correlated with EB, plasma NEFA, BHB, and glucose, as well as milk isocitrate, glucose, and creatinine. Concentrations of major milk FA presented some of the best associations with other indicators of metabolic status, lipomobilization, and EB, and their responses were concordant during early lactation and experimental nutrient restriction. Research is warranted using larger data sets and statistical approaches that can handle multicollinearity typical of milk FA composition data, combine multiple predictive variables, and include model validation.

\section{ACKNOWLEDGMENTS}

The authors thank the staff at Herbipole Research farm of Theix (INRA, UE1414, Theix, France) for cow care, protocol implementation and sampling; K. Pawłowski (Warsaw University of Life Sciences, Warsaw, Poland), J. Rouel, D. Bany, S. Bes, C. Labonne, E. Tixier, and M. Tourret (INRAE, UMR1213, Saint-
Genes-Champanelle, France) for protocol implementation, sample collection, plasma and milk FA analyses; and J. Clausen and C. Berthelsen (Aarhus University, Tjele, Denmark) for milk metabolite analyses. This research was funded in part by the Ruminflame and Longhealth projects of the GISA metaprogram of INRAE (Paris, France). The authors have not stated any conflicts of interest.

\section{REFERENCES}

Allen, M. S. 2014. Drives and limits to feed intake in ruminants. Anim. Prod. Sci. 54:1513-1524. https://doi.org/10.1071/AN14478.

Bell, A. W., and D. E. Bauman. 1997. Adaptations of glucose metabolism during pregnancy and lactation. J. Mammary Gland Biol. Neoplasia 2:265-278. https://doi.org/10.1023/A:1026336505343.

Bernard, L., H. Fougère, T. Larsen, and J. Pires. 2020. Short communication: Diets supplemented with starch and corn oil, marine algae, or hydrogenated palm oil differently affect selected metabolite concentrations in cow and goat milk. J. Dairy Sci. 103:5647-5653. https://doi.org/10.3168/jds.2019-18008.

Billa, P.-A., Y. Faulconnier, T. Larsen, C. Leroux, and J. Pires. 2020 Milk metabolites as noninvasive indicators of nutritional status of mid-lactation Holstein and Montbéliarde cows. J. Dairy Sci. 103:3133-3146. https://doi.org/10.3168/jds.2019-17466.

Bjerre-Harpøth, V., N. C. Friggens, V. M. Thorup, T. Larsen, B. M. Damgaard, K. L. Ingvartsen, and K. M. Moyes. 2012. Metabolic and production profiles of dairy cows in response to decreased nutrient density to increase physiological imbalance at different stages of lactation. J. Dairy Sci. 95:2362-2380. https://doi.org/10 $.3168 /$ jds.2011-4419.

Butler, S. T. 2014. Nutritional management to optimize fertility of dairy cows in pasture-based systems. Animal 8:15-26. https://doi .org/10.1017/S1751731114000834.

Chagas, L. M., M. C. Lucy, P. J. Back, D. Blache, J. M. Lee, P. J. S. Gore, A. J. Sheahan, and J. R. Roche. 2009. Insulin resistance in divergent strains of Holstein-Friesian dairy cows offered fresh pasture and increasing amounts of concentrate in early lactation. J. Dairy Sci. 92:216-222. https://doi.org/10.3168/jds.2008-1329.

Chaiyabutr, N., A. Faulkner, and M. Peaker. 1981. Changes in the concentrations of the minor constituents of goat's milk during starvation and on refeeding of the lactating animal and their relationship to mammary gland metabolism. Br. J. Nutr. 45:149-157. https://doi.org/10.1079/BJN19810087.

Chilliard, Y., A. Ferlay, R. M. Mansbridge, and M. Doreau. 2000. Ruminant milk fat plasticity: Nutritional control of saturated, polyunsaturated, trans and conjugated fatty acids. Ann. Zootech. 49:181-205. https://doi.org/10.1051/animres:2000117.

Dórea, J. R. R., E. A. French, and L. E. Armentano. 2017. Use of milk fatty acids to estimate plasma nonesterified fatty acid concentrations as an indicator of animal energy balance. J. Dairy Sci. 100:6164-6176. https://doi.org/10.3168/jds.2016-12466.

Doreau, M. 1983. Influence de la prise alimentaire sur les variations de différents constituants plasmatiques chez la vache en fin de gestation et en début de lactation. Ann. Rech. Vet. 14:39-48. https:// hal.archives-ouvertes.fr/hal-00901398.

Enjalbert, F., M. C. Nicot, C. Bayourthe, and R. Moncoulon. 2001. Ketone bodies in milk and blood of dairy cows: Relationship between concentrations and utilization for detection of subclinical ketosis. J. Dairy Sci. 84:583-589. https://doi.org/10.3168/jds.S0022 $-0302(01) 74511-0$.

Erdmann, S., M. Derno, C. T. Schäff, S. Börner, U. Kautzsch, B Kuhla, H. M. Hammon, A. Tuchscherer, and M. Röntgen. 2019. Comparative analyses of estimated and calorimetrically determined energy balance in high-yielding dairy cows. J. Dairy Sci. 102:4002-4013. https://doi.org/10.3168/jds.2018-15017.

Foldager, L., C. Gaillard, M. T. Sorensen, T. Larsen, E. Matthews, R. O'Flaherty, F. Carter, M. A. Crowe, C. Grelet, M. Salavati, 
M. Hostens, K. L. Ingvartsen, and M. A. Krogh. 2020. Predicting physiological imbalance in Holstein dairy cows by three different sets of milk biomarkers. Prev. Vet. Med. 179:105006. https://doi .org/10.1016/j.prevetmed.2020.105006.

Friggens, N. C., C. Ridder, and P. Lovendahl. 2007. On the use of milk composition measures to predict the energy balance of dairy cows. J. Dairy Sci. 90:5453-5467. https://doi.org/10.3168/jds.2006-821.

Gelfert, C. C., and R. Staufenbiel. 1998. Proper sampling and handling of blood samples to secure reliable results for the diagnosis of metabolic disturbances in cattle. Prakt. Tierarzt 79:640-650.

Grelet, C., C. Bastin, M. Gelé, J. B. Davière, M. Johan, A. Werner, R. Reding, J. A. Fernandez Pierna, F. G. Colinet, P. Dardenne, N. Gengler, H. Soyeurt, and F. Dehareng. 2016. Development of Fourier transform mid-infrared calibrations to predict acetone, $\beta$-hydroxybutyrate, and citrate contents in bovine milk through a European dairy network. J. Dairy Sci. 99:4816-4825. https://doi .org/10.3168/jds.2015-10477.

Gross, J., H. A. van Dorland, R. M. Bruckmaier, and F. J. Schwarz. 2011a. Milk fatty acid profile related to energy balance in dairy cows. J. Dairy Res. 78:479-488. https://doi.org/10.1017/ S0022029911000550.

Gross, J., H. A. van Dorland, R. M. Bruckmaier, and F. J. Schwarz. 2011b. Performance and metabolic profile of dairy cows during a lactational and deliberately induced negative energy balance with subsequent realimentation. J. Dairy Sci. 94:1820-1830. https://doi .org/10.3168/jds.2010-3707.

Grummer, R. R. 1993. Etiology of lipid-related metabolic disorders in periparturient dairy cows. J. Dairy Sci. 76:3882-3896. https://doi .org/10.3168/jds.S0022-0302(93)77729-2.

Hammon, D. S., I. M. Evjen, T. R. Dhiman, J. P. Goff, and J. L. Walters. 2006. Neutrophil function and energy status in Holstein cows with uterine health disorders. Vet. Immunol. Immunopathol. 113:21-29. https://doi.org/10.1016/j.vetimm.2006.03.022.

Horst, E. A., S. K. Kvidera, and L. H. Baumgard. 2021. Invited review: The influence of immune activation on transition cow health and performance - A critical evaluation of traditional dogmas. J. Dairy Sci. 104:8380-8410. https://doi.org/10.3168/jds.2021-20330.

Hostens, M., V. Fievez, J. L. M. R. Leroy, J. Van Ranst, B. Vlaeminck, and G. Opsomer. 2012. The fatty acid profile of subcutaneous and abdominal fat in dairy cows with left displacement of the abomasum. J. Dairy Sci. 95:3756-3765. https://doi.org/10.3168/ jds.2011-5092.

INRA. 2007. Alimentation des bovins, ovins et caprins. Besoins des animaux - Valeur des aliments. Editions Quae.

Jorjong, S., A. T. M. van Knegsel, J. Verwaeren, R. M. Bruckmaier, B. De Baets, B. Kemp, and V. Fievez. 2015. Milk fatty acids as possible biomarkers to diagnose hyperketonemia in early lactation. J. Dairy Sci. 98:5211-5221. https://doi.org/10.3168/jds.2014-8728.

Jorjong, S., A. T. M. van Knegsel, J. Verwaeren, M. V. Lahoz, R. M. Bruckmaier, B. De Baets, B. Kemp, and V. Fievez. 2014. Milk fatty acids as possible biomarkers to early diagnose elevated concentrations of blood plasma nonesterified fatty acids in dairy cows. J. Dairy Sci. 97:7054-7064. https://doi.org/10.3168/jds.2014-8039.

Larsen, M., A. L. F. Hellwing, T. Larsen, P. Løvendahl, J. Sehested, and M. R. Weisbjerg. 2017. Creatinine in milk as biomarker for muscle protein mobilisation in postpartum cows. Page 407 in Proc. 68th Annual Meeting of the European Federation of Animal Science, Tallinn, Estonia. Wageningen Academic Publishers. https:// doi.org/10.3920/978-90-8686-859-9.

Larsen, T., L. Alstrup, and M. R. Weisbjerg. 2016. Minor milk constituents are affected by protein concentration and forage digestibility in the feed ration. J. Dairy Res. 83:12-19. https://doi.org/ $10.1017 /$ S0022029915000692.

Larsen, T., and K. M. Moyes. 2010. Fluorometric determination of uric acid in bovine milk. J. Dairy Res. 77:438-444. https://doi.org/10 $.1017 /$ S0022029910000580.

Larsen, T., and K. M. Moyes. 2015. Are free glucose and glucose-6-phosphate in milk indicators of specific physiological states in the cow? Animal 9:86-93. https://doi.org/10.1017/S1751731114002043.

Larsen, T., C. M. Røntved, K. L. Ingvartsen, L. Vels, and M. Bjerring. 2010. Enzyme activity and acute phase proteins in milk utilized as indicators of acute clinical E. coli LPS-induced mastitis. Animal 4:1672-1679. https://doi.org/10.1017/S1751731110000947.

Leiber, F., R. Hochstrasser, H. R. Wettstein, and M. Kreuzer. 2011. Feeding transition cows with oilseeds: Effects on fatty acid composition of adipose tissue, colostrum and milk. Livest. Sci. 138:1-12. https://doi.org/10.1016/j.livsci.2010.11.016.

Lerch, S., J. A. A. Pires, C. Delavaud, K. J. Shingfield, D. Pomies, B. Martin, Y. Chilliard, and A. Ferlay. 2015. Rapeseed or linseed in dairy cow diets over 2 consecutive lactations: Effects on adipose fatty acid profile and carry-over effects on milk fat composition in subsequent early lactation. J. Dairy Sci. 98:1005-1018. https://doi .org/10.3168/jds.2014-8578.

Mahrt, A., O. Burfeind, and W. Heuwieser. 2014. Effects of time and sampling location on concentrations of $\beta$-hydroxybutyric acid in dairy cows. J. Dairy Sci. 97:291-298. https://doi.org/10.3168/jds .2013-7099.

McNamara, S., J. J. Murphy, M. Rath, and F. P. O'Mara. 2003. Effects of different transition diets on energy balance, blood metabolites and reproductive performance in dairy cows. Livest. Prod. Sci. 84:195-206. https://doi.org/10.1016/S0301-6226(03)00093-9.

Megahed, A. A., M. W. H. Hiew, D. Ragland, and P. D. Constable. 2019. Changes in skeletal muscle thickness and echogenicity and plasma creatinine concentration as indicators of protein and intramuscular fat mobilization in periparturient dairy cows. J. Dairy Sci. 102:5550-5565. https://doi.org/10.3168/jds.2018-15063.

Nielsen, N. I., K. L. Ingvartsen, and T. Larsen. 2003. Diurnal variation and the effect of feed restriction on plasma and milk metabolites in TMR-fed dairy cows. J. Vet. Med. A Physiol. Pathol. Clin. Med. 50:88-97. https://doi.org/10.1046/j.1439-0442.2003.00496.x.

Oetzel, G. R. 2004. Monitoring and testing dairy herds for metabolic disease. Vet. Clin. North Am. Food Anim. Pract. 20:651-674. https://doi.org/10.1016/j.cvfa.2004.06.006.

Overton, T. R., J. A. A. McArt, and D. V. Nydam. 2017. A 100year review: Metabolic health indicators and management of dairy cattle. J. Dairy Sci. 100:10398-10417. https://doi.org/10.3168/jds 2017-13054

Parker, B. J., and R. W. Blowey. 1974. A comparison of blood from the jugular vein and coccygeal artery and vein of cows. Vet. Rec. 95:14-18. https://doi.org/10.1136/vr.95.1.14.

Pawłowski, K., C. Leroux, Y. Faulconnier, C. Boby, A. De La Foye, D. Durand, and J. Pires. 2016. Liver transcriptome modifications by nutrient restriction in early lactation Holstein cows challenged with intramammary lipopolysaccharide. J. Dairy Sci. 99(E-Suppl. 1):58. (Abstr.)

Pawłowski, K., J. A. A. Pires, Y. Faulconnier, C. Chambon, P. Germon, C. Boby, and C. Leroux. 2019. Mammary gland transcriptome and proteome modifications by nutrient restriction in early lactation Holstein cows challenged with intra-mammary lipopolysaccharide. Int. J. Mol. Sci. 20:1156. https://doi.org/10.3390/ijms20051156.

Piantoni, P., C. M. Ylioja, and M. S. Allen. 2015. Feed intake is related to changes in plasma nonesterified fatty acid concentration and hepatic acetyl CoA content following feeding in lactating dairy cows. J. Dairy Sci. 98:6839-6847. https://doi.org/10.3168/jds.2014 -9085 .

Pires, J. A. A., Y. Chilliard, C. Delavaud, J. Rouel, D. Pomiès, and F. Blanc. 2015. Physiological adaptations and ovarian cyclicity of Holstein and Montbéliarde cows under two low-input production systems. Animal 9:1986-1995. https://doi.org/10.1017/ S1751731115001317.

Pires, J. A. A., C. Delavaud, Y. Faulconnier, D. Pomies, and Y. Chilliard. 2013. Effects of body condition score at calving on indicators of fat and protein mobilization of periparturient Holstein-Friesian cows. J. Dairy Sci. 96:6423-6439. https://doi.org/10.3168/jds.2013 $-6801$.

Pires, J. A. A., T. Larsen, and C. Leroux. 2021. Supplemental tables and figures for "Milk metabolites and fatty acids as noninvasive biomarkers of metabolic status and energy balance in early lactation cows," J. Dairy Sci. https://doi.org/10.5281/zenodo.5137874.

Pires, J. A. A., K. Pawłowski, J. Rouel, C. Delavaud, G. Foucras, P. Germon, and C. Leroux. 2019. Undernutrition modified metabolic responses to intramammary lipopolysaccharide but had limited ef- 
fects on selected inflammation indicators in early-lactation cows. J. Dairy Sci. 102:5347-5360. https://doi.org/10.3168/jds.2018-15446.

Pralle, R. S., and H. M. White. 2020. Big data, big predictions: Utilizing milk Fourier-transform infrared and genomics to improve hyperketonemia management. J. Dairy Sci. 103:3867-3873. https:/ /doi.org/10.3168/jds.2019-17379.

Roberts, T., N. Chapinal, S. J. LeBlanc, D. F. Kelton, J. Dubuc, and T. F. Duffield. 2012. Metabolic parameters in transition cows as indicators for early-lactation culling risk. J. Dairy Sci. 95:30573063. https://doi.org/10.3168/jds.2011-4937.

Saxton, A. M. 1998. A macro for converting mean separation output to letter groupings. Pages 1243-1246 in Proc. 23rd SAS Users Group Intl. SAS Institute Inc.

Scalia, D., N. Lacetera, U. Bernabucci, K. Demeyere, L. Duchateau, and C. Burvenich. 2006. In vitro effects of nonesterified fatty acids on bovine neutrophils oxidative burst and viability. J. Dairy Sci. 89:147-154. https://doi.org/10.3168/jds.S0022-0302(06)72078-1.

Seely, C. R., K. D. Bach, D. M. Barbano, and J. A. A. McArt. 2021. Effect of hyperketonemia on the diurnal patterns of energy-related blood metabolites in early-lactation dairy cows. J. Dairy Sci. 104:818-825. https://doi.org/10.3168/jds.2020-18930.

Thorup, V. M., D. Edwards, and N. C. Friggens. 2012. On-farm estimation of energy balance in dairy cows using only frequent body weight measurements and body condition score. J. Dairy Sci. 95:1784-1793. https://doi.org/10.3168/jds.2011-4631.

Vlaeminck, B., R. Gervais, M. M. Rahman, F. Gadeyne, M. Gorniak, M. Doreau, and V. Fievez. 2015. Postruminal synthesis modifies the odd- and branched-chain fatty acid profile from the duodenum to milk. J. Dairy Sci. 98:4829-4840. https://doi.org/10.3168/jds 2014-9207.

Wei, T., and V. Simko. 2017. R package "corrplot": Visualization of a correlation matrix. Version 0.84. Accessed Jun. 29, 2021. https:// github.com/taiyun/corrplot.
Wylie, A. R. G., S. Woods, A. F. Carson, and M. McCoy. 2008. Periprandial changes in metabolite and metabolic hormone concentrations in high-genetic-merit dairy heifers and their relationship to energy balance in early lactation. J. Dairy Sci. 91:577-586. https: //doi.org/10.3168/jds.2007-0388.

Xu, W., A. van Knegsel, E. Saccenti, R. van Hoeij, B. Kemp, and J. Vervoort. 2020a. Metabolomics of milk reflects a negative energy balance in cows. J. Proteome Res. 19:2942-2949. https://doi.org/ 10.1021/acs.jproteome.9b00706.

Xu, W., J. Vervoort, E. Saccenti, B. Kemp, R. J. van Hoeij, and A. T. M. van Knegsel. 2020b. Relationship between energy balance and metabolic profiles in plasma and milk of dairy cows in early lactation. J. Dairy Sci. 103:4795-4805. https://doi.org/10.3168/ jds.2019-17777.

Xu, W., J. Vervoort, E. Saccenti, R. van Hoeij, B. Kemp, and A. van Knegsel. 2018. Milk metabolomics data reveal the energy balance of individual dairy cows in early lactation. Sci. Rep. 8:15828. https: //doi.org/10.1038/s41598-018-34190-4.

Zachut, M., G. Kra, Y. Portnik, F. Shapiro, and N. Silanikove. 2016. Milk glucose-6-phosphate dehydrogenase activity and glucose6-phosphate are associated with oxidative stress and serve as indicators of energy balance in dairy cows. RSC Advances 6:6541265417. https://doi.org/10.1039/C6RA11924G.

\section{ORCIDS}

J. A. A. Pires @ https://orcid.org/0000-0002-3773-9293

T. Larsen (ㄴ) https://orcid.org/0000-0003-3058-5938

C. Leroux @ https://orcid.org/0000-0001-6835-3978 